\title{
Experiments and Electromechanical Properties of a Broadband Piezoelectric Vibration Energy Harvester
}

\author{
Guangqing Wang, Shuaishuai Gao, and Xiaojun Li \\ School of Information and Electronic Engineering, Zhejiang Gongshang University, No. 18, Xuezheng Street, \\ Xiasha University Town, Hangzhou 310018, China
}

Correspondence should be addressed to Guangqing Wang; kele76@163.com

Received 11 March 2015; Revised 12 October 2015; Accepted 13 October 2015

Academic Editor: Nerio Tullini

Copyright (C) 2016 Guangqing Wang et al. This is an open access article distributed under the Creative Commons Attribution License, which permits unrestricted use, distribution, and reproduction in any medium, provided the original work is properly cited.

\begin{abstract}
A broadband piezoelectric energy harvester (BPEH), consisting of a conventional linear piezoelectric energy harvester (CPEH) and an elastic magnifier, was presented in this paper. The improved two-degree-of-freedom lumped-parameter electromechanical model of the BPEH was established and the optimal external resistances under short-circuit and open-circuit resonance conditions were investigated to maximize the output power of the $\mathrm{BPEH}$. The output voltage and output power of the BPEH obtained from the theoretical model were verified and found to be in reasonable agreement with the experimental results. The obtained results have shown that the maximal output powers under short-circuit and open-circuit resonance conditions are both 24 times that generated by the $\mathrm{CPEH}$ without elastic magnifier. The frequency space between the two peaks of the frequency-response curve of the BPEH is $14 \mathrm{~Hz}$ which is 7 times that of $\mathrm{CPEH}$.
\end{abstract}

\section{Introduction}

The power requirements of small electronic devices have reduced drastically. This has motivated research into the possibilities of powering these devices by harvesting the vibrational energy available in their environments and using it to generate electricity. The ultimate objective is to remove the requirement of an external power source or battery replacement for small electronic devices, particularly when they are used in remote locations [1-3]. The basic transduction mechanisms that can be used to convert ambient vibrational energy to electrical energy are piezoelectric, electrostatic, and electromagnetic transductions [4-6]. Among these transduction mechanisms, piezoelectric transduction has attracted immense attention because of its low cost and high power density [7], and piezoelectric transducers such as conventional piezoelectric energy harvester (CPEH) are the simplest transducers to fabricate and are well suited to smallscale systems $[8,9]$.

Typically, a CPEH is a cantilevered unimorph/bimorph beam with or without a tip mass. The cantilevered beam is attached to a vibrating host structure and is therefore subjected to a base excitation. Because the base excitation is always assumed to be harmonic, a well-known singledegree-of-freedom (SDOF) harmonic base excitation relationship has been widely used for modeling the dynamics [10] and parameter optimization [11]. However, an important issue in CPEH is that the maximum output power of the device is limited to a narrow bandwidth around the base resonant frequency. If the excitation frequency shifts slightly from the resonant condition, the output power is drastically decreased. To overcome this bandwidth issue of the $\mathrm{CPEH}$, two innovative methods have been considered by researchers. One method is to tune the resonant frequency of the $\mathrm{CPEH}$ to match the ambient vibration frequency at all times [1214]. The other method is to broaden the bandwidth with various approaches, including nonlinear oscillation techniques $[15,16]$, a multimodal energy harvester method [17], and coupled elastic structures $[18,19]$. Other methods such as optimizing the parameters of the energy harvester [20] and impedance-matching technology [21] have also been proposed to improve the output power of the CPEH.

A dynamic magnifier has been extensively integrated into $\mathrm{CPEH}$ to improve the output power in recent studies. 


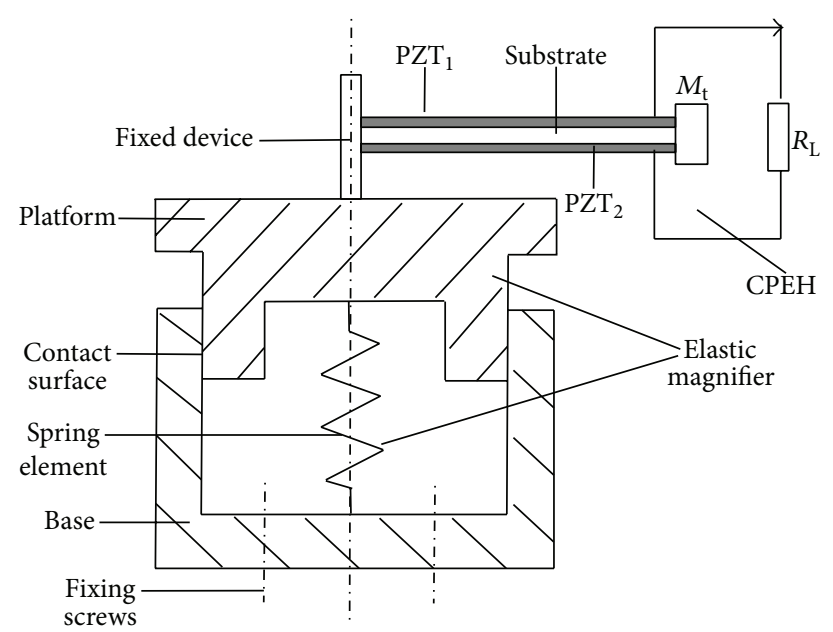

FIgURE 1: Configuration of proposed BPEH.

Wang et al. [22] proposed an energy harvester combining a piezoelectric cantilever with a SDOF elastic magnifier to improve the output power of the CPEH. The distributed parameter model of the energy harvester was developed based on Hamilton's principle and Rayleigh-Ritz method. But the validity of the developed mathematical model should be verified by some experiments. Ma et al. [23] incorporated a dynamic magnifier, which works through the interaction of coupled elastic structures, into a CPEH to amplify the output power, and a two-degree-of-freedom (TDOF) lumped parameter model was derived. However, the developed mathematical model does not take into account in detail the electromechanical coupling between the mechanical and electrical fields and does not consider the effect of the design parameters of the dynamic magnifier or the external resistance on the output power of the energy harvester. Li et al. [24] investigated a miniature electric generator consisting of piezoelectric benders and elastic magnifier and derived the lumped parameter analytical model. The developed model, however, ignores the effect of the dynamic mode shape and the strain distribution of the CPEH and the electrical loads on the output power. Aldraihem and Baz [25] established the electromechanical coupling model of piezorods with a dynamic magnifier and studied the effect of the design parameters of the dynamic magnifier on the output power. Arafa et al. [26] implemented experiments to demonstrate the feasibility of a CPEH with a dynamic magnifier. Tang and Zuo [27] established a TDOF lumped parameter model to investigate the optimal output power of $\mathrm{CPEH}$ with a dynamic magnifier. These researches mainly focused on the maximum output power that could be achieved by ignoring the damping of the dynamic magnifier. Moreover, the TDOF lumped parameter models also ignored the strain distribution and the dynamic mode shape of the CPEH, which is critical to affect the electromechanical properties.

Despite the documented potential and advantages of the $\mathrm{CPEH}$ with dynamic magnifier, it has been shown that there is room for improvement and advancement for this device. One principle challenge is the accurate mathematical model required to evaluate quickly the effect of parameter variation on the device and to calculate the maximum power harvesting performance. As abovementioned studies that present the TDOF lumped parameter models ignored the strain distribution and the dynamic mode shape of the CPEH and did not consider the effect of the dynamic magnifier damping on the output power, this research presents an improved TDOF lumped parameter electromechanical model of the $\mathrm{BPEH}$. The developed mathematical model takes into account the strain distribution and the dynamic mode shape of the $\mathrm{CPEH}$ as well as the effect of the dynamic magnifier damping and the external resistance on the output power. The effects of some important parameters, such as the mass, stiffness, and damping ratios between the $\mathrm{CPEH}$ and the elastic magnifier, on the output properties of the BPEH were numerically studied. The optimal external resistances under short-circuit and open-circuit resonance conditions were investigated to maximize the output power of the BPEH. Finally, the output voltage and output power of the BPEH obtained from the theoretical model were verified and found to be in reasonable agreement with the experimental results. The obtained results verify the validity of the improved lumped parameter model of the BPEH.

\section{Structure of the Proposed BPEH}

The configuration of the proposed BPEH is shown in Figure 1. It consists of a CPEH and an elastic magnifier. The $\mathrm{CPEH}$ consists of a bimorph piezoelectric cantilever with a tip mass $\left(M_{\mathrm{t}}\right)$. Two piezoelectric plates $\left(\mathrm{PZT}_{1}\right.$ and $\left.\mathrm{PZT}_{2}\right)$ oppositely polarized in the thickness direction are perfectly bonded to the top and bottom, respectively, of the substrate beam. The piezoelectric bimorph plates are connected in series. The electrode pairs covering the top and bottom faces of the piezoelectric plates are assumed to be thin so that their contribution to the thickness dimension is negligible. A simple electrical circuit consisting of a resistive load $\left(R_{\mathrm{L}}\right)$ is directly connected to the output terminal of the harvester. The elastic magnifier consists of a platform and a spring element, 
and it is positioned between the $\mathrm{CPEH}$ and the base. The base is fixed on the vibration source using fixing screws. When an ambient vibration is generated in the base, the vibration amplitude of the CPEH will be amplified through the elastic magnifier.

\section{Improved Lumped Parameter Electromechanical Model of BPEH}

The improved electromechanical coupling model of $\mathrm{BPEH}$ is shown in Figure 2. The equivalent mass, equivalent damping, and equivalent stiffness of the CPEH are denoted by $M_{\mathrm{eq}}, C_{\mathrm{eq}}$, and $K_{\text {eq }}$, respectively; $\alpha$ and $C_{\mathrm{p}}$ represent the electromechanical coupling factor and the electrical capacitance of the PZTs, respectively; $M_{b}, C_{b}$, and $K_{b}$ represent the platform mass, the friction damping of the contact surface, and the stiffness of the spring element of the elastic magnifier, respectively; $u_{b}$, $y_{b}$, and $y_{s}$ denote the vibration displacements of the base, platform mass $M_{b}$, and equivalent mass $M_{\mathrm{eq}}$, respectively; and $V$ is the voltage of the load resistance $R_{\mathrm{L}}$.

3.1. Definitions of Improved Model Parameters. Unlike previous studies [23-27], the improved model takes into account the important information on the dynamic mode shape and strain distribution of the CPEH. This important information is involved in the key parameters of equivalent mass $M_{\mathrm{eq}}$ and stiffness $K_{\text {eq }}$ of the CPEH. Assuming the equivalent mass $M_{\text {eq }}$ and stiffness $K_{\mathrm{eq}}$ of the CPEH takes the following forms [28]:

$$
\begin{aligned}
& M_{\mathrm{eq}}=\beta_{M} \rho A L+M_{\mathrm{t}}, \\
& K_{\mathrm{eq}}=\frac{\beta_{K} E I}{L^{3}},
\end{aligned}
$$

where $\rho A$ and $E I$ are the average mass and bending stiffness of the $\mathrm{CPEH}$, respectively, and $L$ is the length of cantilevered beam of the CPEH. $\beta_{M}$ and $\beta_{K}$ are coefficients, which relate to the dynamic mode shape and strain distribution of the $\mathrm{CPEH}$, and they can be determined based on the energy conservation principle. Let $w(x)$ be the dynamic bending deflection of the CPEH shown in Figure 1, and the relationship between the deflection and the bending mode shape $\phi(x)$ takes the following form:

$$
w(x)=\mu(x) \phi(x)
$$

where $\mu(x)$ is the proportional factor and $\phi(x)$ is the bending mode shape of the CPEH. Based on the elastic mechanics theories, the factor $\mu(x)$ can be calculated as

$$
\mu(x)=\frac{w(x)}{\phi(x)}=\frac{M_{\mathrm{t}} g x^{2}(3 L-x)}{6 E I \phi(x)},
$$

where $g$ is gravitational acceleration.
From (2) and (3), the equivalent mass and stiffness of the $\mathrm{CPEH}$ without the tip mass $M_{\mathrm{t}}$ can be obtained as follows according to the energy conservation principle:

$$
\begin{aligned}
m_{\mathrm{eq}} & =\int_{0}^{L} \rho A\left[\frac{\bar{\mu}(x) \phi(x)}{\bar{\mu}(L) \phi(L)}\right]^{2} d x, \\
k_{\mathrm{eq}} & =\frac{L^{3} M_{\mathrm{t}} g}{E I \mu(L) \phi(L)} \cdot \frac{E I}{L^{3}} .
\end{aligned}
$$

Comparing (4) with the first term of the right-hand side of (1), respectively, the coefficients $\beta_{M}$ and $\beta_{K}$ can be determined:

$$
\begin{aligned}
& \beta_{M}=\frac{\int_{0}^{L}[\mu(x) \phi(x)]^{2} d x}{[\mu(L) \phi(L)]^{2} L}, \\
& \beta_{K}=\frac{L^{3} M_{\mathrm{t}} g}{E I \mu(L) \phi(L)} .
\end{aligned}
$$

The electromechanical coupling factor $\alpha$ and electrical capacitance $C_{p}$ of the PZTs can be defined according to the well-known piezoelectric constitutive equation and the relationships between the stress and the strain of the $\mathrm{CPEH}$, respectively $[29,30]$ :

$$
\begin{aligned}
\alpha & =\frac{\beta_{\alpha} e_{31} b\left(h_{\mathrm{s}}+h_{\mathrm{p}}\right)}{(2 L)}, \\
C_{\mathrm{p}} & =\frac{b L \varepsilon_{33}^{S}}{\left(2 h_{\mathrm{p}}\right)},
\end{aligned}
$$

where $\beta_{\alpha}=-L d \phi(x) /\left.d x\right|_{x=L} ; e_{31}$ and $\varepsilon_{33}^{S}$ are the piezoelectric and clamped dielectric constants, respectively; $h_{\mathrm{s}}$ and $h_{\mathrm{p}}$ are the thickness of the metal substrate and the PZTs, respectively; and $b$ is the width of the cantilevered beam.

The damping factor $\xi_{\text {eq }}$ of $\mathrm{CPEH}$ is related to the logarithmic decrement $\delta$ for underdamped vibrations via the following relationship [31]:

$$
\xi_{\mathrm{eq}}=\frac{\delta}{\sqrt{(2 \pi)^{2}+(\delta)^{2}}} \quad \text { where } \delta=\ln \left(\frac{A_{k}}{A_{k+1}}\right) \text {, }
$$

where $A_{k}$ and $A_{k+1}$ are any two successive amplitudes when the cantilever beam exhibits oscillation. Figure 3 shows the system used to test the damping factor of the $\mathrm{CPEH}$. The $\mathrm{CPEH}$ vibrated in damped oscillation when it was excited by the hammer's impulse force. The tip displacement of the $\mathrm{CPEH}$ was detected by a laser displacement sensor (LDS) and was transferred to a data acquisition unit (DAU). The displacement waveform was displayed by personal computer (PC).

The stiffness $K_{b}$ of the spring element of elastic magnifier was determined through experiments. Figure 4 shows the setup used to test the spring element stiffness. One end of the spring element was fixed on the pothook. Some standard mass pieces $(1 \mathrm{~kg} /$ piece) were loaded onto the other end of the spring element, which extended the spring element. 


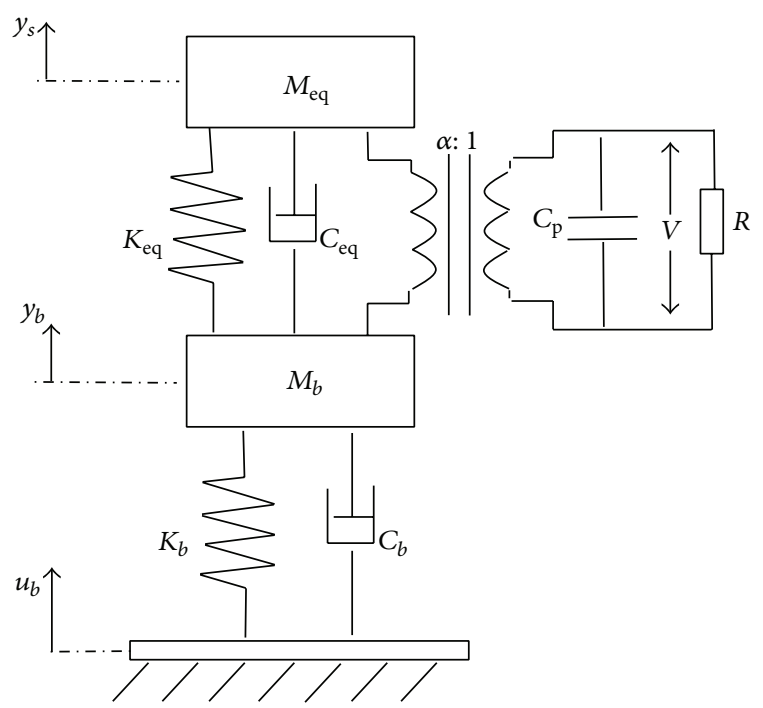

FIGURE 2: Improved lumped parameter electromechanical model of BPEH.
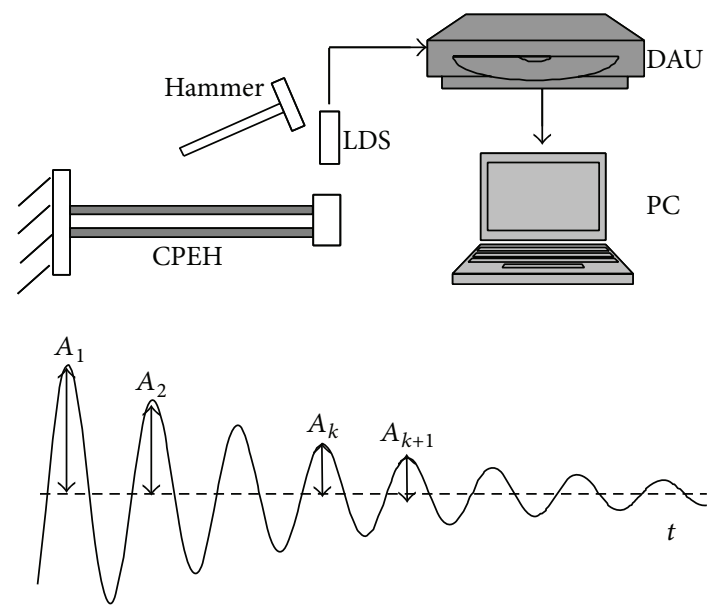

FIGURE 3: Test of damping factor of CPEH.

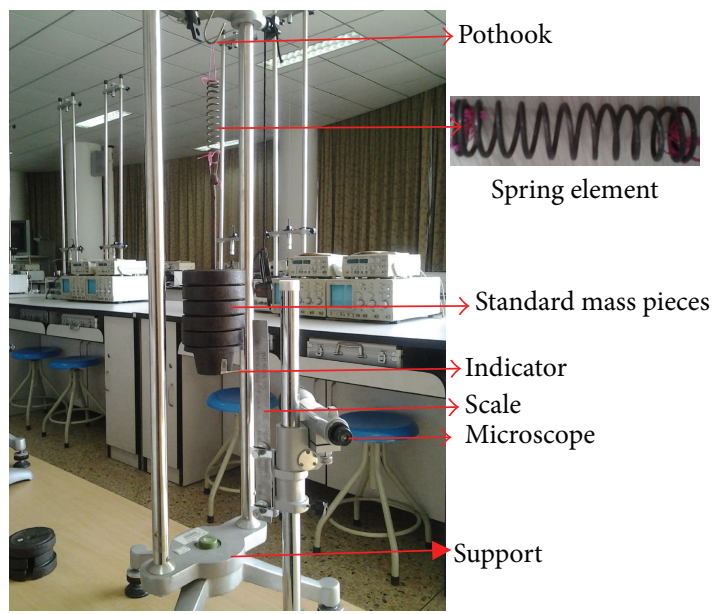

FIGURE 4: Test setup for the spring element stiffness.
The elongation $(\Delta L)$ of the spring element was then observed using the indicator on the scale through the microscope. The force $(F)$ acting on the spring element can be defined through calculating the number $(N)$ of the standard mass pieces, by using $F=N \times g$, where $g$ is the gravity acceleration. Thus, the stiffness of the spring element can be calculated as

$$
K_{b}=\frac{F}{\left((1 / n) \sum_{i=1}^{n} \Delta L_{i}\right)}=\frac{N g}{\left((1 / n) \sum_{i=1}^{n} \Delta L_{i}\right)},
$$

where $n$ is the testing number of the elongation of the spring element.

3.2. Governing Equations of the Improved Electromechanical Model. The governing equations for the improved model shown in Figure 2 are then obtained:

$$
\begin{aligned}
& {\left[\begin{array}{ccc}
M_{\mathrm{eq}} & 0 & 0 \\
0 & M_{b} & 0 \\
0 & 0 & 0
\end{array}\right]\left\{\begin{array}{c}
\ddot{y}_{s} \\
\ddot{y}_{b} \\
\ddot{V}
\end{array}\right\}} \\
& +\left[\begin{array}{ccc}
C_{\mathrm{eq}} & -C_{\mathrm{eq}} & 0 \\
-C_{\mathrm{eq}} & C_{\mathrm{eq}}+C_{b} & 0 \\
\alpha & -\alpha & -C_{\mathrm{p}}
\end{array}\right]\left\{\begin{array}{l}
\dot{y}_{s} \\
\dot{y}_{b} \\
\dot{V}
\end{array}\right\} \\
& +\left[\begin{array}{ccc}
K_{\mathrm{eq}} & -K_{\mathrm{eq}} & \alpha \\
-K_{\mathrm{eq}} & K_{\mathrm{eq}}+K_{b} & 0 \\
0 & 0 & -\frac{1}{R_{\mathrm{L}}}
\end{array}\right]\left\{\begin{array}{l}
y_{s} \\
y_{b} \\
V
\end{array}\right\} \\
& =\left[\begin{array}{c}
0 \\
C_{b} \\
0
\end{array}\right] \dot{u}_{b}+\left[\begin{array}{c}
0 \\
K_{b} \\
0
\end{array}\right] u_{b} .
\end{aligned}
$$

Assuming that the base is vibrating in a harmonic manner, $u_{b}(t), y_{b}(t)$, and $y_{s}(t)$ have the following forms:

$$
\begin{aligned}
& u_{b}(t)=U_{b} e^{i \omega t}, \\
& y_{b}(t)=Y_{b} e^{i \omega t}, \\
& y_{s}(t)=Y_{s} e^{i \omega t},
\end{aligned}
$$

where $U_{b}$ is the amplitude of the harmonic vibration at frequency $\omega . Y_{b}$ and $Y_{s}$ are the vibration amplitudes of $M_{b}$ and $M_{\text {eq }}$, respectively. The output voltage of the load resistance $R_{\mathrm{L}}$ can be expressed as

$$
V(t)=V_{0} e^{i \omega t}
$$

Substituting (10) and (11) into (9), we can obtain the relative displacement $\bar{y}_{b}$ (the displacement of mass $M_{b}$ with respect to the base displacement); the relative tip velocity $\bar{v}_{s}$ (the velocity of mass $M_{\text {eq }}$ with respect to the base acceleration); the relative output voltage $\bar{V}_{0}$ (the output voltage of load resistance $R_{\mathrm{L}}$ with respect to the base acceleration); and the relative output power $\bar{P}_{0}$ (the output power of load resistance $R_{\mathrm{L}}$ with respect to the base acceleration square) as follows: 


$$
\begin{aligned}
& \bar{y}_{b}=\frac{y_{b}(t)}{u_{b}(t)}=\frac{A_{0}+r}{1+r-a \Omega^{2}+2 A_{0}(1+d)-\left(1+A_{0}\right)\left(1+A_{0}+B_{0}\right) /\left(1-\Omega^{2}+A_{0}+B_{0}\right)}, \\
& \bar{v}_{s}=\frac{\dot{y}_{s}(t)}{\ddot{u}_{b}(t)}=-\frac{j}{\omega} \cdot \frac{A_{0}+B_{0}}{1-\Omega^{2}+A_{0}+B_{0}} \bar{y}_{b}, \\
& \bar{V}_{0}=\frac{V(t)}{\ddot{u}_{b}(t)}=\frac{C_{0}\left(\Omega^{2}-1\right)}{-\omega^{2}\left(1-\Omega^{2}+A_{0}+B_{0}\right)} \cdot \bar{y}_{b}, \\
& \bar{P}_{0}=\frac{P(t)}{\ddot{u}_{b}^{2}(t)}=\frac{\bar{V}_{0}^{2}}{R_{\mathrm{L}}}
\end{aligned}
$$

where $A_{0}=2 j \xi_{\mathrm{eq}} \Omega, B_{0}=\theta \Omega k^{2} j /(1+\theta \Omega j), C_{0}=$ $\alpha \omega j /\left(C_{\mathrm{p}} \omega j+1 / R_{\mathrm{L}}\right), a=M_{b} / M_{\mathrm{eq}}, r=K_{b} / K_{\mathrm{eq}}, d=$ $C_{b} / C_{\mathrm{eq}}, \Omega=\omega / \omega_{\mathrm{eq}}, \xi_{\mathrm{eq}}=C_{\mathrm{eq}} /\left(2 M_{\mathrm{eq}} \omega_{\mathrm{eq}}\right), \theta=\omega_{\mathrm{eq}} R_{\mathrm{L}} C_{\mathrm{p}}$, $k^{2}=\alpha^{2} /\left(K_{\mathrm{eq}} C_{\mathrm{p}}\right), g=\omega_{\mathrm{eq}} / \omega_{b}, \omega_{b}=\sqrt{K_{b} / M_{b}}$, and $\omega_{\mathrm{eq}}=$ $\sqrt{K_{\text {eq }} / M_{\text {eq }}}$.

From (9), we can obtain the resonance frequency and antiresonance frequency of the $\mathrm{BPEH}$ :

$$
\begin{aligned}
f_{\mathrm{r}} & =f_{\text {eq }} \\
f_{\text {anti }} & =\sqrt{1+k^{2}} f_{\text {eq }},
\end{aligned}
$$

where $f_{\text {eq }}=\omega_{\text {eq }} /(2 \pi)$ is the resonance frequency of the CPEH.
To guarantee that the BPEH has more output power over a frequency bandwidth ranging from $f_{\mathrm{r}}$ to $f_{\text {anti }}$ than a constituent $\mathrm{CPEH}$, the amplitude of the minimum displacement $\left|y_{s}(t)\right|$ occurring at $f=f_{\text {eq }}$ within the frequency range must satisfy the following relationship:

$$
\min \left(\left|y_{s}(t)\right|\right)>\left|y_{s}^{\mathrm{CPEH}}(t)\right|
$$

where $y_{s}^{\mathrm{CPEH}}(t)$ is the tip displacement of the CPEH at $f=$ $f_{\text {eq }}$, and it can be expressed as

$$
y_{s}^{\mathrm{CPEH}}(t)=\frac{j 2 \xi_{\mathrm{eq}} \omega_{\mathrm{eq}} \omega+\omega_{\mathrm{eq}}^{2}+C_{0} / M_{\mathrm{eq}}}{j 2 \xi_{\mathrm{eq}} \omega_{\mathrm{eq}} \omega+\omega_{\mathrm{eq}}^{2}-\omega^{2}+C_{0} / M_{\mathrm{eq}}} u_{b}(t)
$$

The tip displacement $y_{s}(t)$ of the BPEH can be obtained from (13) as follows:

$$
y_{s}(t)=\frac{A_{0}+B_{0}}{1-\Omega^{2}+A_{0}+B_{0}} \cdot \frac{A_{0}+r}{1+r-a \Omega^{2}+2 A_{0}(1+d)-\left(1+A_{0}\right)\left(1+A_{0}+B_{0}\right) /\left(1-\Omega^{2}+A_{0}+B_{0}\right)} u_{b}(t) .
$$

From (17) the critical mass ratio $a_{c}$ can be determined. When $a>a_{c}$, the electrical output of the BPEH is larger than that of the CPEH over a frequency range between $f_{\mathrm{r}}$ and $f_{\text {anti }}$.

\section{Numerical Analysis}

Numerical calculations were carried out to analyze the performances of the BPEH using MATLAB software. The material and geometric parameters of the CPEH for numerical calculations are listed in Table 1 . The set of parameters of the cantilever beam is chosen here only for testing the validity of the $\mathrm{BPEH}$; further details of how the parameters are chosen can be found in [32].

Figure 5 shows the relative motion, $\bar{y}_{b}$, of mass $M_{b}$ of the BPEH with various mass ratios $a$ when $g=1$ and $R_{\mathrm{L}}=1 \mathrm{k} \Omega$. It indicates that the BPEH has two peaks that are sensitive to the mass ratio. As the mass ratio $a$ increases, the left peak decreases and the right peak increases, and the distance between the two peaks narrows, forming a wideband frequency window. Moreover, for a given mass $M_{\mathrm{eq}}$ of the $\mathrm{CPEH}$, when the mass ratio $a=1 e-10$ and the stiffness ratio $r=1 e+10$, resp., the elastic magnifier becomes rigid and the $\mathrm{BPEH}$ shown in Figure 1 reduces to a $\mathrm{CPEH}$. The vibration amplifying role of the elastic magnifier disappears, so that the relative motion curve of mass $M_{b}$ is a line and is identical to that of the CPEH shown in Figure 5.

Figure 6 shows the tip relative velocity, $\bar{v}_{s}$, of the piezoelectric cantilever of the BPEH with different mass ratios $a$ when $g=1$ and $R_{\mathrm{L}}=1 \mathrm{k} \Omega$. The tip relative velocity, $\bar{v}_{s}$, of the piezoelectric cantilever is also sensitive to the mass ratio. As the mass ratio $a$ increases, the left peak increases and the right peak decreases. This indicates that some mechanical energy of the elastic magnifier is transferred to the piezoelectric cantilever. Particularly, when the mass ratio $a=20$, there is a minimum tip velocity between the two peaks, which is equal to the maximum tip velocity of the CPEH. Thus, we 
TABLE 1: Material and geometric parameters of the CPEH.

\begin{tabular}{lc}
\hline Item & Value \\
\hline Piezoelectric plate density $\rho_{\mathrm{p}}\left(\mathrm{kg} / \mathrm{m}^{3}\right)$ & 7450 \\
Substrate plate density $\rho_{\mathrm{s}}\left(\mathrm{kg} / \mathrm{m}^{3}\right)$ & 8920 \\
Piezoelectric plate stiffness $E_{\mathrm{p}}(\mathrm{GPa})$ & 28.45 \\
Substrate plate stiffness $E_{\mathrm{s}}(\mathrm{GPa})$ & 113 \\
Strain constant $d_{31}(\mathrm{C} / \mathrm{m})$ & $-190 \times 10^{-12}$ \\
Stress constant $e_{31}(\mathrm{C} / \mathrm{m})$ & -4.08 \\
Vacuum permittivity $\varepsilon_{0}(\mathrm{~F} / \mathrm{m})$ & $8.854 \times 10^{-12}$ \\
Absolute permittivity $\varepsilon_{33}(\mathrm{~F} / \mathrm{m})$ & $1200 \varepsilon_{0}$ \\
Beam length $L(\mathrm{~mm})$ & 50.8 \\
Beam width $b(\mathrm{~mm})$ & 30.8 \\
Piezoelectric plate thickness $h_{\mathrm{p}}(\mathrm{mm})$ & 0.26 \\
Substrate plate thickness $h_{\mathrm{s}}(\mathrm{mm})$ & 0.15 \\
Damping ratio of elastic magnifier $\xi_{b}$ & 0.002 \\
Damping ratio of piezoelectric beam $\xi_{\mathrm{eq}}$ & 0.02 \\
Tip mass $M_{\mathrm{t}}(\mathrm{kg})$ & 0.011 \\
Load resistance $R_{\mathrm{L}}(\Omega)$ & 1000 \\
\hline
\end{tabular}

can determine the critical mass ratio $a_{c}=20$ when $g=1$ and $R_{\mathrm{L}}=1 \mathrm{k} \Omega$.

Figures 7 and 8 show the output voltage $\bar{V}_{0}$ and the output power $\bar{P}_{0}$ of the BPEH with different mass ratios $a$ when $g=1$ and $R_{\mathrm{L}}=1 \mathrm{k} \Omega$. A semilogarithmic coordinate is used for clarifying the difference of each output power curve in Figure 7. The output voltage and the output power behave similarly to the tip relative velocity $\bar{v}_{s}$ of the piezoelectric cantilever (in Figure 5). As the mass ratio $a$ increases, both the output voltage and the output power increase, which indicates that a larger mass ratio $a$ results in higher voltage and output power. Moreover, when the mass ratio $a=$ $1 e-10$ and the stiffness ratio $r=1 e+10$, the voltage and the power curves of the BPEH are identical to those of the $\mathrm{CPEH}$.

Figure 9 shows the effect of the damping ratio $q=\xi_{b} / \xi_{\text {eq }}$ of the BPEH on the output power when $g=1, a=r=20$, and $R_{\mathrm{L}}=1 \mathrm{k} \Omega$. As the damping ratio $q$ increases, the peak power of the BPEH decreases. When the damping coefficient $\xi_{b}$ of the elastic magnifier is larger than that of the $\mathrm{CPEH}$, the dynamic magnified function of the elastic magnifier becomes

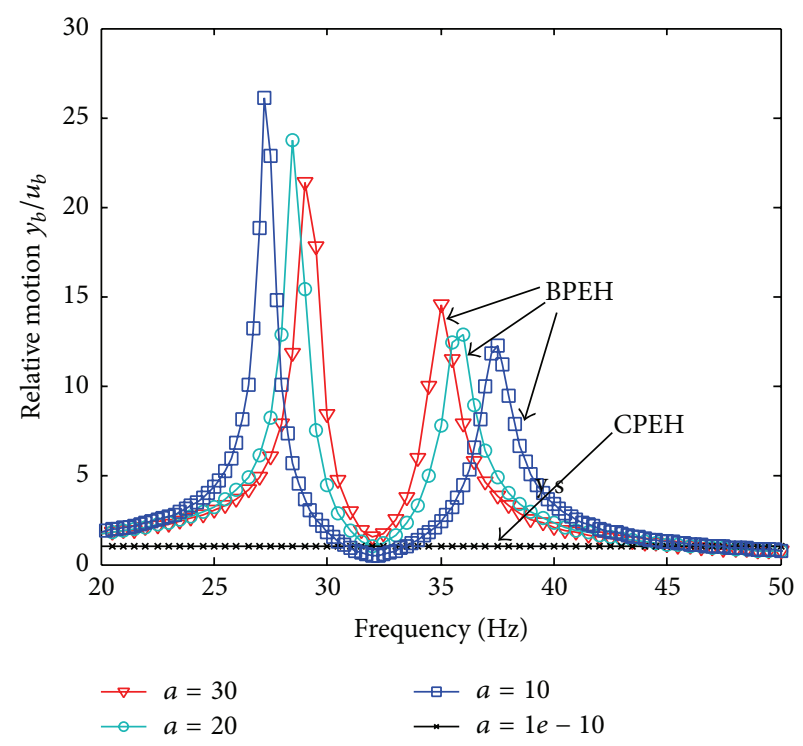

FIGURE 5: Relative displacement $\bar{y}_{b}$ with various $a$ when $g=1$ and $R_{\mathrm{L}}=1 \mathrm{k} \Omega$.

too weak to increase the peak power of the BPEH. This means that a small $\xi_{b}$ or $\xi_{b}=0$ of the elastic magnifier is suitable for enhancing the output power of the BPEH. So the damping coefficient $\xi_{b}$ of the elastic magnifier is zero in the following research.

\section{Optimal Resistance Load and Output Power}

Suppose $g, a, r, \Omega$, and $q$ of the BPEH are fixed except for the load resistance $R_{\mathrm{L}}$; then, we can obtain the design criterion for reaching maximum power flow under steady-state operation by tuning the load resistance $R_{\mathrm{L}}$ according to the following expression:

$$
\left.\frac{\partial}{\partial R_{\mathrm{L}}} \bar{P}_{0}\left(g, a, r, \Omega, q, R_{\mathrm{L}}\right)\right|_{g, a, r, \Omega, q}=0 .
$$

The notation $R_{\mathrm{L}}^{\mathrm{opt}}$ is used to represent the solution of (20), where the superscript "opt" denotes functions evaluated at the optimal load resistance $R_{\mathrm{L}}^{\mathrm{opt}}$. The optimization problem of the BPEH is formulated as follows:

$$
\left\langle\text { Find the optimal load resistance } R_{\mathrm{L}}^{\mathrm{opt}} \text { that maximizes } \bar{P}_{0}\left(g, a, r, \Omega, q, R_{\mathrm{L}}^{\mathrm{opt}}\right)\right\rangle \text {. }
$$

Figure 10 shows the output power $\bar{P}_{0}$ of the BPEH with various load resistances at the resonant frequency $\left(f_{\mathrm{r}}^{\prime}=\right.$ $31.9 \mathrm{~Hz})$ and antiresonant frequency $\left(f_{\mathrm{ar}}^{\prime}=32.3 \mathrm{~Hz}\right)$ of CPEH. Both power curves show peak values that correspond to the optimal load resistance. According to (20), the two optimal load resistances calculated under resonant and antiresonant states are $136 \mathrm{k} \Omega$ and $177 \mathrm{k} \Omega$, which are identified in Figure 10 as $R_{\mathrm{L}-\mathrm{r}}^{\mathrm{opt}}$ and $R_{\mathrm{L}-\mathrm{ar}}^{\mathrm{opt}}$, respectively.
Figure 11 shows the optimal output power $\bar{P}_{0}^{\text {opt }}$ of the BPEH with changing excitation frequencies at the two optimal load resistances when $g=1$ and $a=r=$ 20. As can be seen in Figure 11, the peak output power generated at a load resistance of $136 \mathrm{k} \Omega$ is close to that generated at a load resistance of $177 \mathrm{k} \Omega$. Thus, the use of matching load resistances under resonance and antiresonance frequency conditions produces almost the same 


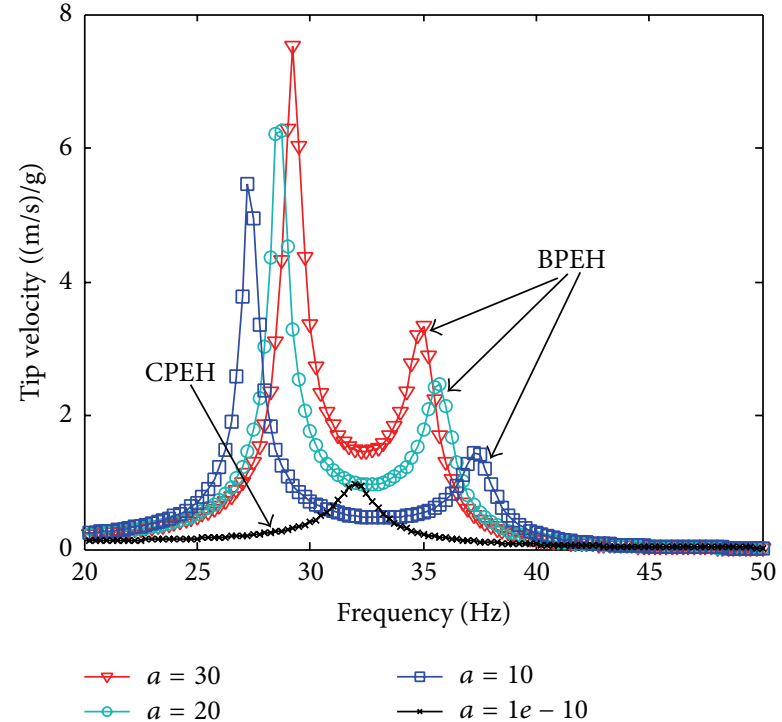

FIGURE 6: Tip relative velocity $\bar{v}_{s}$ with various $a$ when $g=1$ and $R_{\mathrm{L}}$ $=1 \mathrm{k} \Omega$.

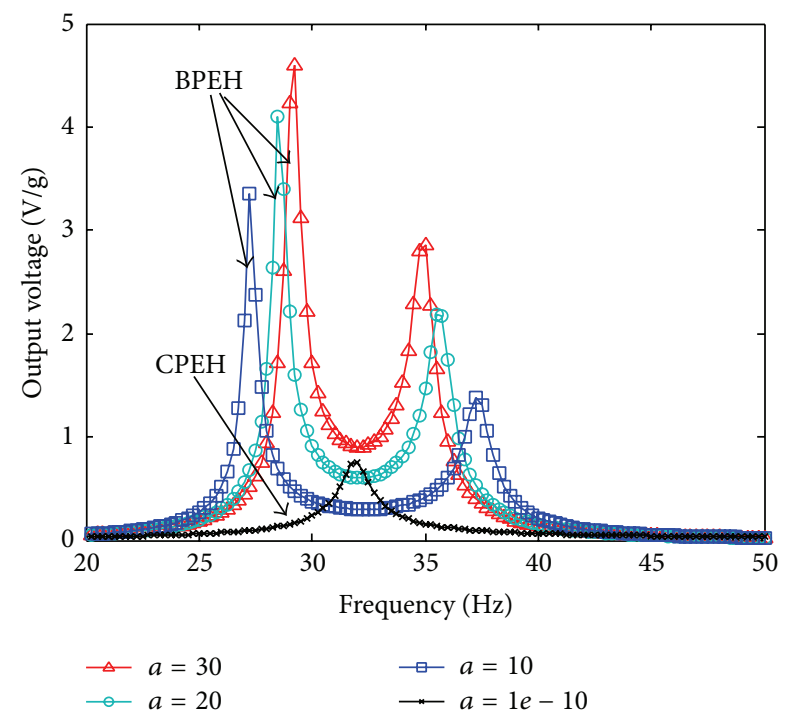

FIgURE 7: Output voltage $\bar{V}_{0}$ with various $a$ when $g=1$ and $R_{\mathrm{L}}=$ $1 \mathrm{k} \Omega$.

amount of maximum power although they have different voltage and current outputs. Table 2 lists the resonance frequency and the output power of the BPEH with two different load resistances of $136 \mathrm{k} \Omega$ and $177 \mathrm{k} \Omega$, respectively. From Table 2, we can obtain that the frequency bandwidth of $\mathrm{BPEH}$ is $7 \mathrm{~Hz}$, which is about 16 times that of $\mathrm{CPEH}$, and the peak output power of the $\mathrm{BPEH}$ under resonance and antiresonance frequency conditions is almost 40 times that generated by the CPEH. The analytical results indicate that the $\mathrm{BPEH}$ cannot only enhance the output performances but also broaden the frequency bandwidth.

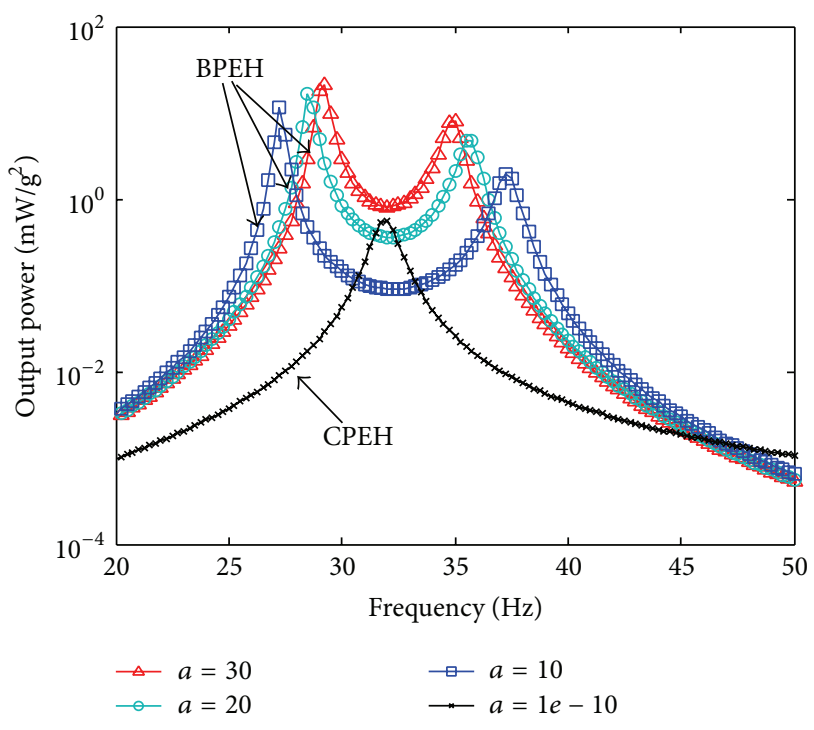

FIGURE 8: Output power $\bar{P}_{0}$ with various $a$ when $g=1$ and $R_{\mathrm{L}}=$ $1 \mathrm{k} \Omega$.

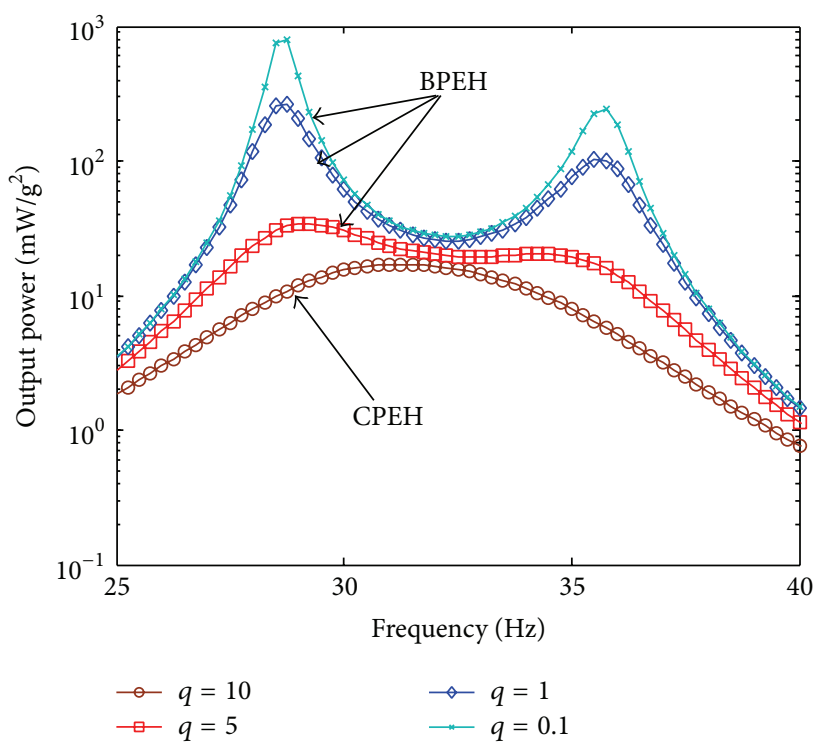

Figure 9: Output power $\bar{P}_{0}$ with various $q$ when $g=1, a=r=20$, and $R_{\mathrm{L}}=1 \mathrm{k} \Omega$.

\section{Experimental Verification of the Numerical Results}

6.1. Prototype Model Arrangement. The value of the mass ratio should be as large as possible for the design of a highperformance $\mathrm{BPEH}$. Here, we present a simple prototype model to explore the main aspects of the BPEH.

The $\mathrm{CPEH}$ and $\mathrm{BPEH}$ prototypes were developed as shown in Figure 12, respectively. The CPEH was made of a phosphor bronze substrate (mass density: $8920 \mathrm{~kg} / \mathrm{m}^{3}$, Young's modulus: $113 \mathrm{GPa}$ ) and two PZT (PZT-5A, mass density: $7450 \mathrm{~kg} / \mathrm{m}^{3}$, Young's modulus: $28.45 \mathrm{GPa}$ ) layers. The equivalent mass $\left(M_{\mathrm{eq}}\right)$ and stiffness $\left(K_{\mathrm{eq}}\right)$ of the CPEH shown 


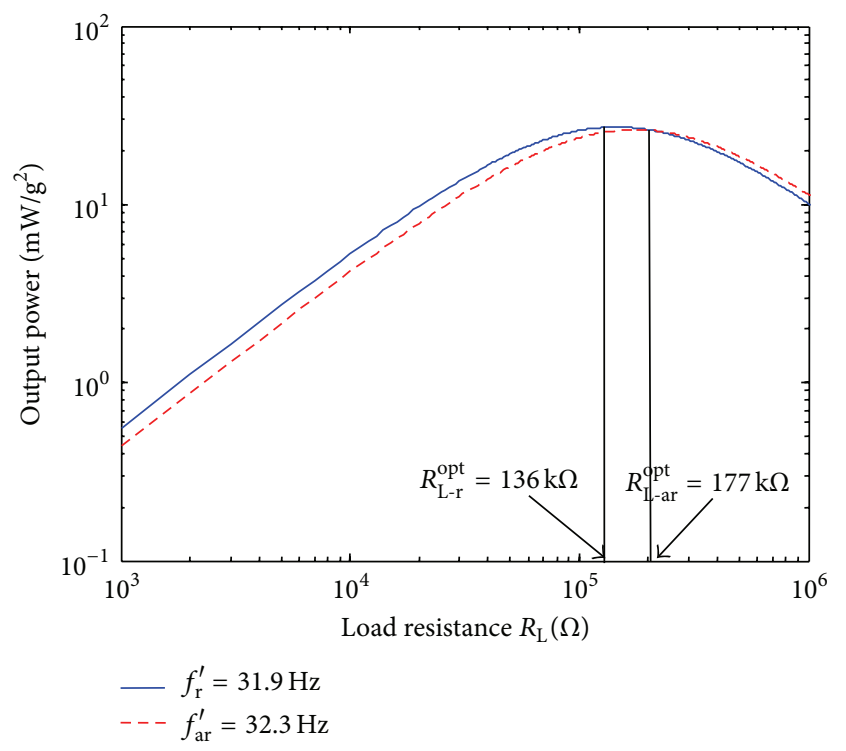

Figure 10: Output power $\bar{P}_{0}$ with various $R_{\mathrm{L}}$ at resonant and antiresonant frequencies of $\mathrm{CPEH}$.

in Figure 12(a) were evaluated to be $12.9 \mathrm{~g}$ and $5.2 \times 10^{2} \mathrm{~N} / \mathrm{m}$, respectively; the mass $\left(M_{b}\right)$ and the stiffness $\left(K_{b}\right)$ of the elastic magnifier were measured to be $123 \mathrm{~g}$ and $7.9 \times 10^{3} \mathrm{~N} / \mathrm{m}$, so the mass ratio $a$ and stiffness ratio $r$ of the BPEH are 10 and 15, respectively.

6.2. Verification of the Numerical Results. The experimental setup used for measuring the voltage-to-base acceleration of $\mathrm{BPEH}$ and $\mathrm{CPEH}$ is shown in Figure 13. The BPEH/CPEH was fixed onto the base platform of the vibrator. An arbitrary waveform generator generated a voltage signal to cause the electromagnetic vibrator (JZ-1) to oscillate and excite the $\mathrm{BPEH} / \mathrm{CPEH}$ to vibrate harmonically. A low mass accelerometer (YJ9A) was used to detect the vibration acceleration of the base platform. A laser beam from a laser displacement sensor (LDS) projects on the tip end of the BPEH/CPEH and is detected also by LDS to become the displacement signal at the tip end of the BPEH/CPEH. Both the acceleration signal $\ddot{u}_{b}(t)$ of the base platform and the tip displacement signal $y_{s}(t)$ of the BPEH/CPEH were acquired by a dynamic signal analyzer (COINV INV1601B) and transformed into the frequency domain. The dynamic response and the resonant frequencies were thus obtained and shown by a personal computer. The output voltage signal $V(t)$ of the BPEH/CPEH was acquired and shown by an oscilloscope. Thus, the output voltage $\bar{V}_{0}$ and the output power $\bar{P}_{0}$ of the load resistance $R_{\mathrm{L}}$ with respect to the base acceleration could be calculated with the following relationships:

$$
\begin{aligned}
& \bar{V}_{0}=\frac{V(t)}{\ddot{u}_{b}}[\mathrm{~V} / \mathrm{g}], \\
& \bar{P}_{0}=\frac{\overline{V^{2}}}{R_{\mathrm{L}}}\left[\mathrm{mW} / \mathrm{g}^{2}\right] .
\end{aligned}
$$

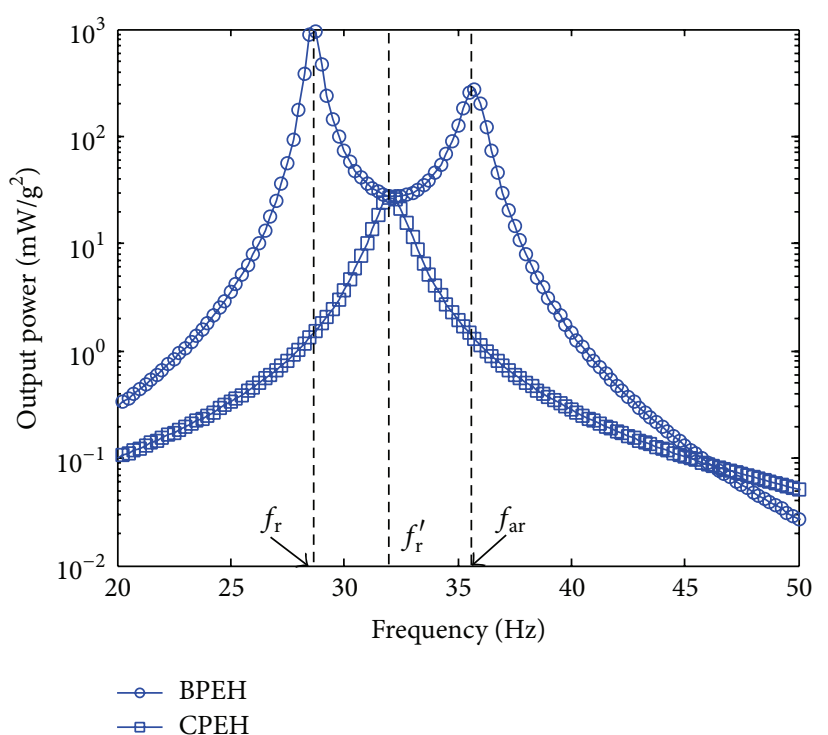

(a) $R_{\mathrm{L}}=136 \mathrm{k} \Omega$

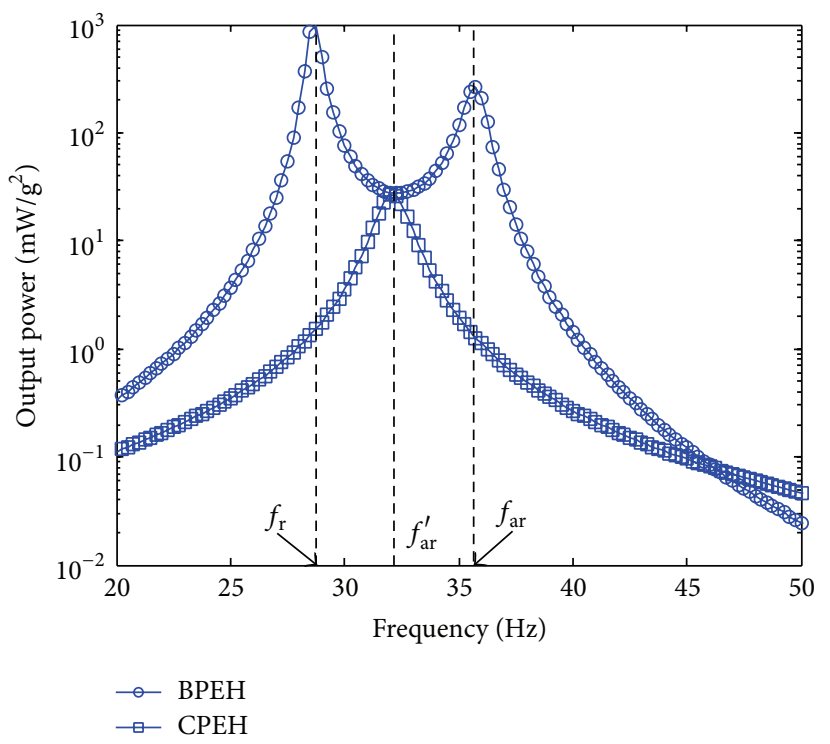

(b) $R_{\mathrm{L}}=177 \mathrm{k} \Omega$

FIGURE 11: Optimal output power of BPEH versus vibration frequency for two optimal load resistances when $g=1$ and $a=r=20$.

Figure 14 shows comparisons of the experimental and theoretical results of the output voltage (Figure 14(a)) and output power (Figure 14(b)) of the CPEH when the load resistance $R_{\mathrm{L}}$ is $3 \mathrm{k} \Omega$ and $470 \mathrm{k} \Omega$, respectively. The maximum output voltage and output power measured are $2.4[\mathrm{~V} / \mathrm{g}]$ and $1.93\left[\mathrm{~mW} / \mathrm{g}^{2}\right]$ when $R_{\mathrm{L}}$ is $3 \mathrm{k} \Omega$, and the maximum voltage and power measured are $104[\mathrm{~V} / \mathrm{g}]$ and $23\left[\mathrm{~mW} / \mathrm{g}^{2}\right]$ when $R_{\mathrm{L}}$ is $470 \mathrm{k} \Omega$. Figure 15 shows the comparisons of the experimental and theoretical results of the output voltage and output power of the $\mathrm{CPEH}$ under resonance state (Figure 15(a)) and antiresonance state (Figure 15(b)), respectively. The comparisons indicate that the theoretical results trace the experimental results reasonably accurately. 
TABLE 2: Analytical results of BPEH with two different load resistances when $a=20$.

\begin{tabular}{lcccc}
\hline \multirow{2}{*}{ Node } & \multicolumn{2}{c}{$R_{\mathrm{L}}=136 \mathrm{k} \Omega$} & \multicolumn{2}{c}{$R_{\mathrm{L}}=177 \mathrm{k} \Omega$} \\
& Frequency $[\mathrm{Hz}]$ & Power $\left[\mathrm{mW} / \mathrm{g}^{2}\right]$ & Frequency $[\mathrm{Hz}]$ & Power $\left[\mathrm{mW} / \mathrm{g}^{2}\right]$ \\
\hline BPEH & & & 28.77 & 1003.81 \\
Left peak & 28.75 & 935.5 & 32.35 & 27.9 \\
Middle well & 31.91 & 27.8 & 35.77 & 268.68 \\
Right peak & 35.75 & 274.8 & 32.35 & 27.9 \\
CPEH & 31.91 & 27.8 & & \\
\hline
\end{tabular}

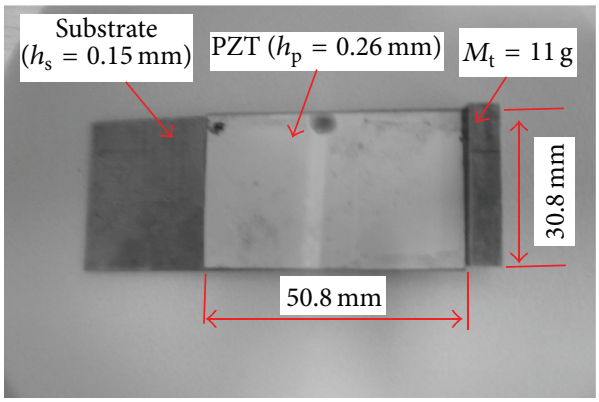

(a) Prototype of $\mathrm{CPEH}$

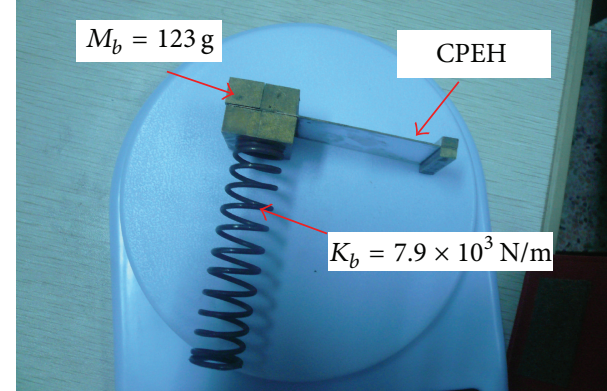

(b) Prototype of BPEH

Figure 12: Prototypes of BPEH and CPEH.

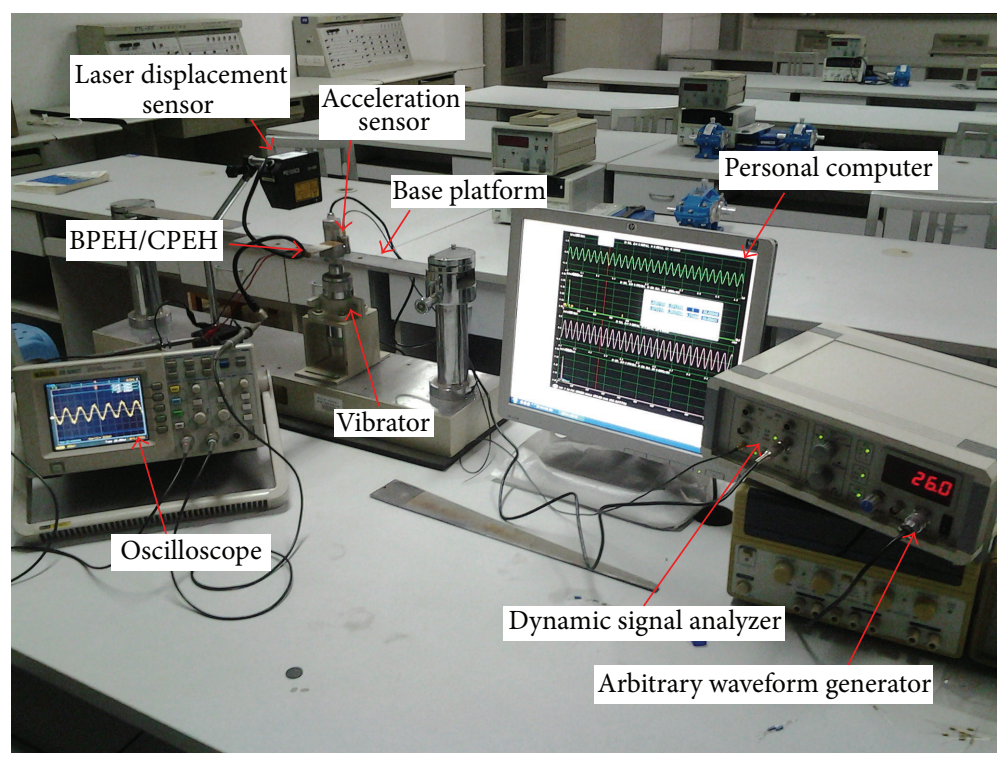

FIGURE 13: Experiment setup for the BPEH and CPEH.

Figure 16 shows comparisons of the experimental and theoretical results of the output voltage and output power of the BPEH when $a=10, r=15$ and the load resistances, $R_{\mathrm{L}}$, are $136 \mathrm{k} \Omega$ and $177 \mathrm{k} \Omega$, respectively. The corresponding comparisons when $a=10, r=7$ at the load resistances, $R_{\mathrm{L}}$, which are $136 \mathrm{k} \Omega$ and $177 \mathrm{k} \Omega$, respectively, are shown in Figure 17. All the comparisons shown in Figures 16 and 17 indicate that the theoretical results trace the experimental results reasonably accurately, which clearly shows the consistency of the coupling lumped parameter model proposed here. The corresponding measured data are listed in Table 3. By changing the stiffness ratio (or the stiffness of the elastic magnifier), different peak voltage and power are recorded. It should be noted that long spring element with small stiffness 


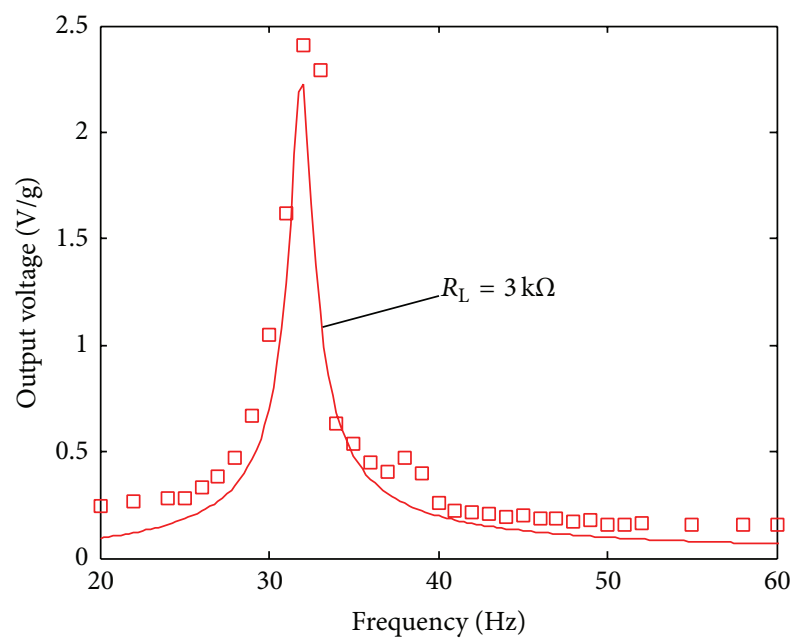

- Experimental

_ Theoretical

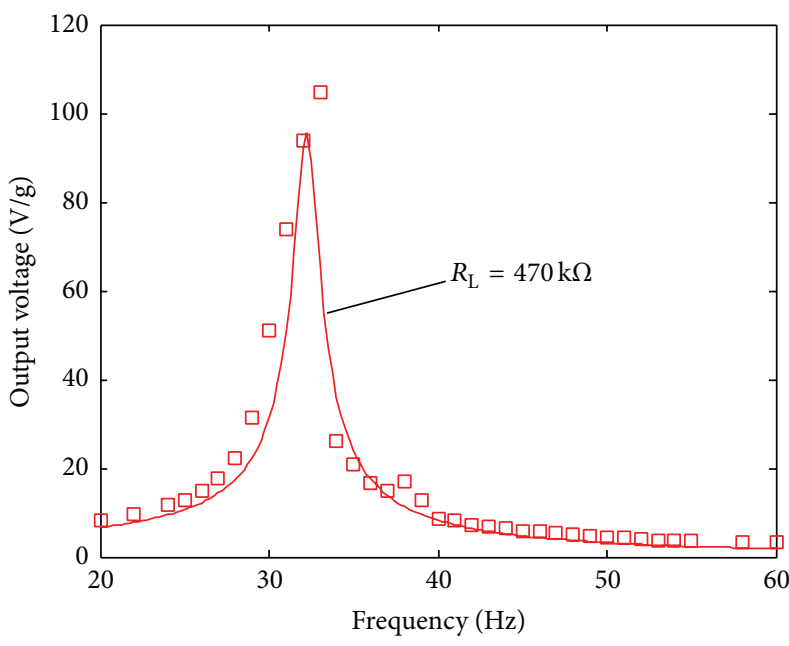

- Experimental

Theoretical

(a) Output voltage
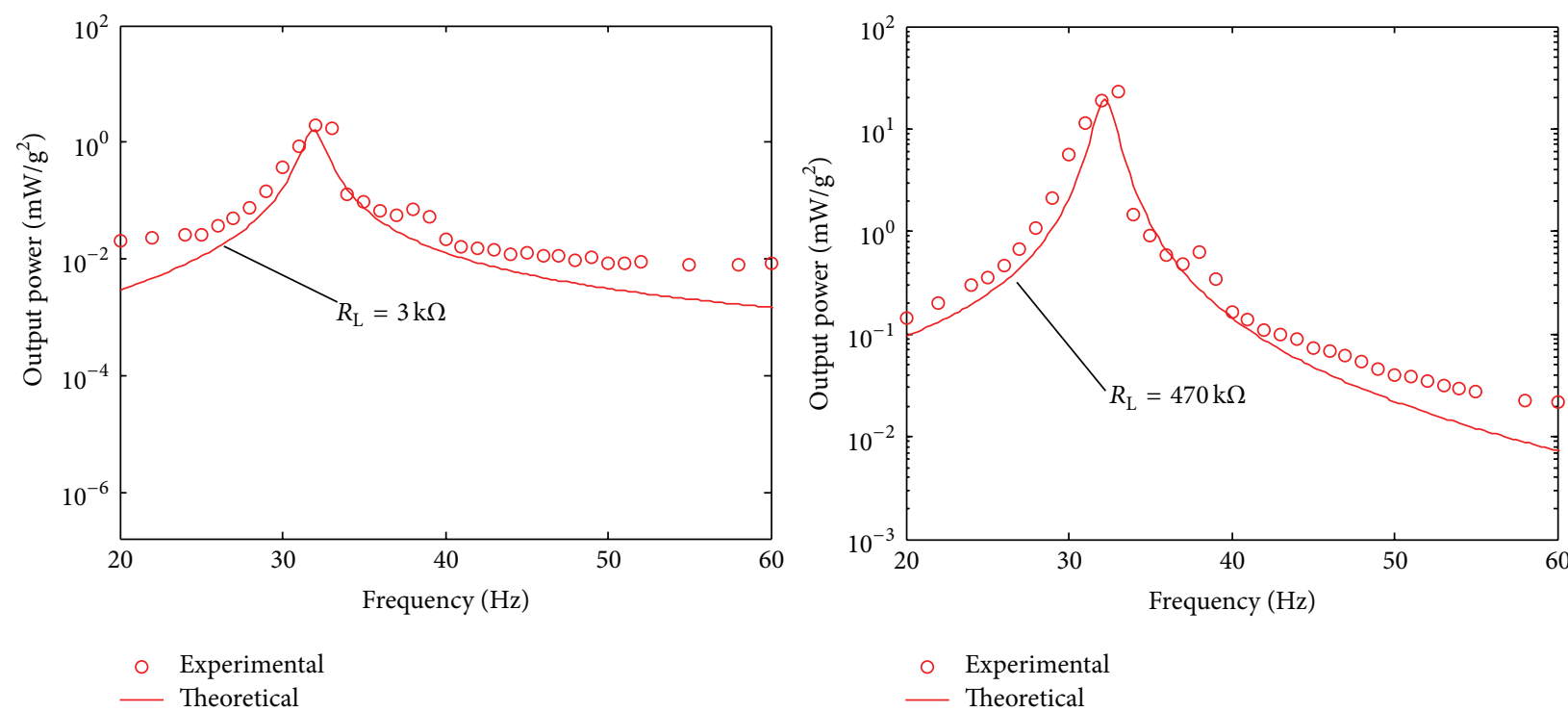

(b) Output power

FIGURE 14: Frequency responses of output voltage and power of the CPEH under different load resistances.

TABLE 3: Measured results of BPEH with different $a, r$ and load resistances $R_{\mathrm{L}}$.

\begin{tabular}{|c|c|c|c|c|}
\hline & \multicolumn{4}{|c|}{$a=10$} \\
\hline & \multicolumn{2}{|c|}{$r=15$} & \multicolumn{2}{|c|}{$r=7$} \\
\hline & $R_{\mathrm{L}}=136 \mathrm{k} \Omega$ & $R_{\mathrm{L}}=177 \mathrm{k} \Omega$ & $R_{\mathrm{L}}=136 \mathrm{k} \Omega$ & $R_{\mathrm{L}}=177 \mathrm{k} \Omega$ \\
\hline \multicolumn{5}{|l|}{ Left peak } \\
\hline Frequency $[\mathrm{Hz}]$ & 33 & 31 & 24 & 24 \\
\hline Voltage [V/g] & 110.8280 & 102.5641 & 271.6418 & 310.8108 \\
\hline Power $\left[\mathrm{mW} / \mathrm{g}^{2}\right]$ & 90.3151 & 59.4316 & 542.5681 & 545.7817 \\
\hline \multicolumn{5}{|l|}{ Middle well } \\
\hline Frequency $[\mathrm{Hz}]$ & 38 & 37 & 32 & 32 \\
\hline Voltage [V/g] & 26.3309 & 25.1998 & 15.1858 & 17.3844 \\
\hline Power $\left[\mathrm{mW} / \mathrm{g}^{2}\right]$ & 5.0979 & 3.5877 & 1.6956 & 1.7074 \\
\hline \multicolumn{5}{|l|}{ Right peak } \\
\hline Frequency $[\mathrm{Hz}]$ & 42 & 42 & 38 & 38 \\
\hline Voltage [V/g] & 226.6667 & 197.5940 & 82.1918 & 95.6522 \\
\hline Power $\left[\mathrm{mW} / \mathrm{g}^{2}\right]$ & 377.7778 & 220.5760 & 49.6727 & 51.6912 \\
\hline
\end{tabular}



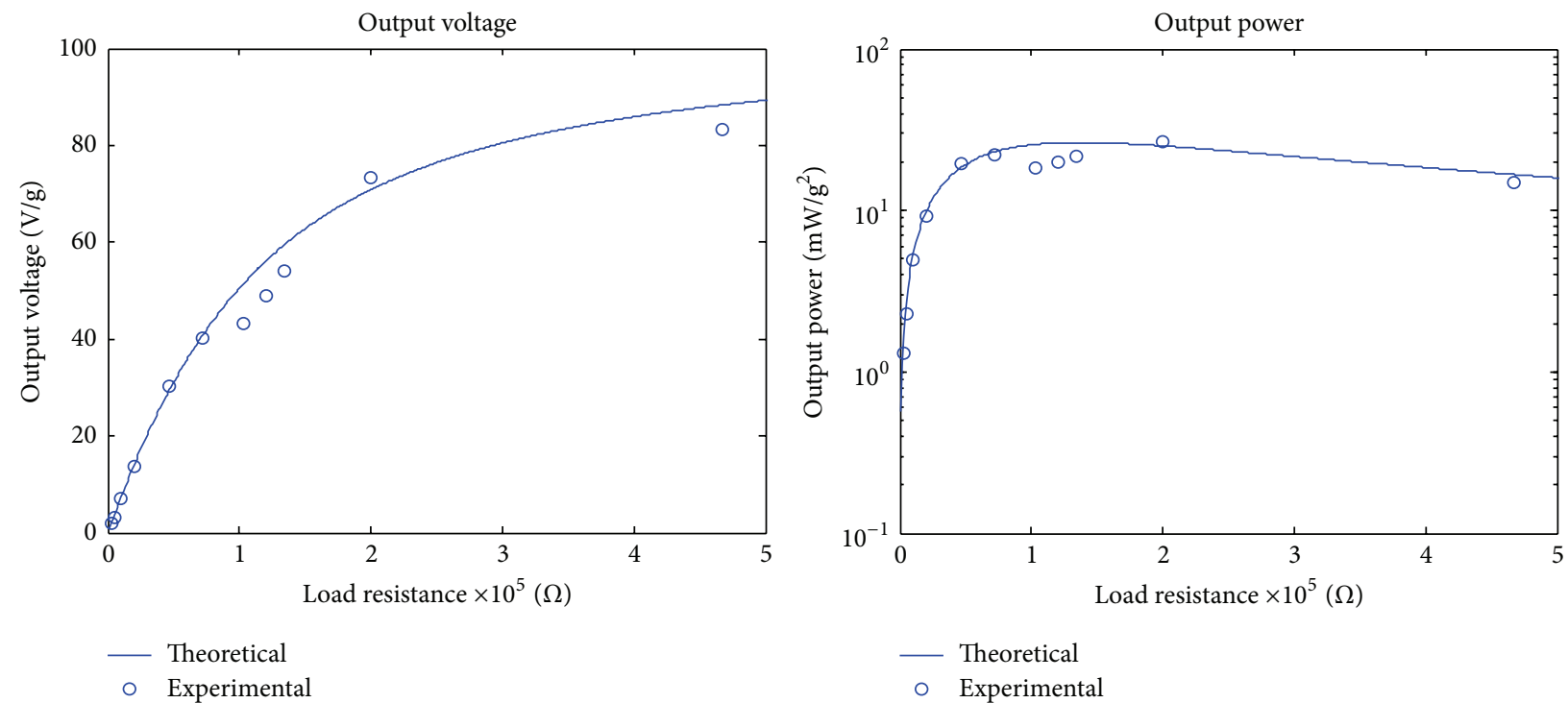

(a) Resonance state $f=31.905 \mathrm{~Hz}$
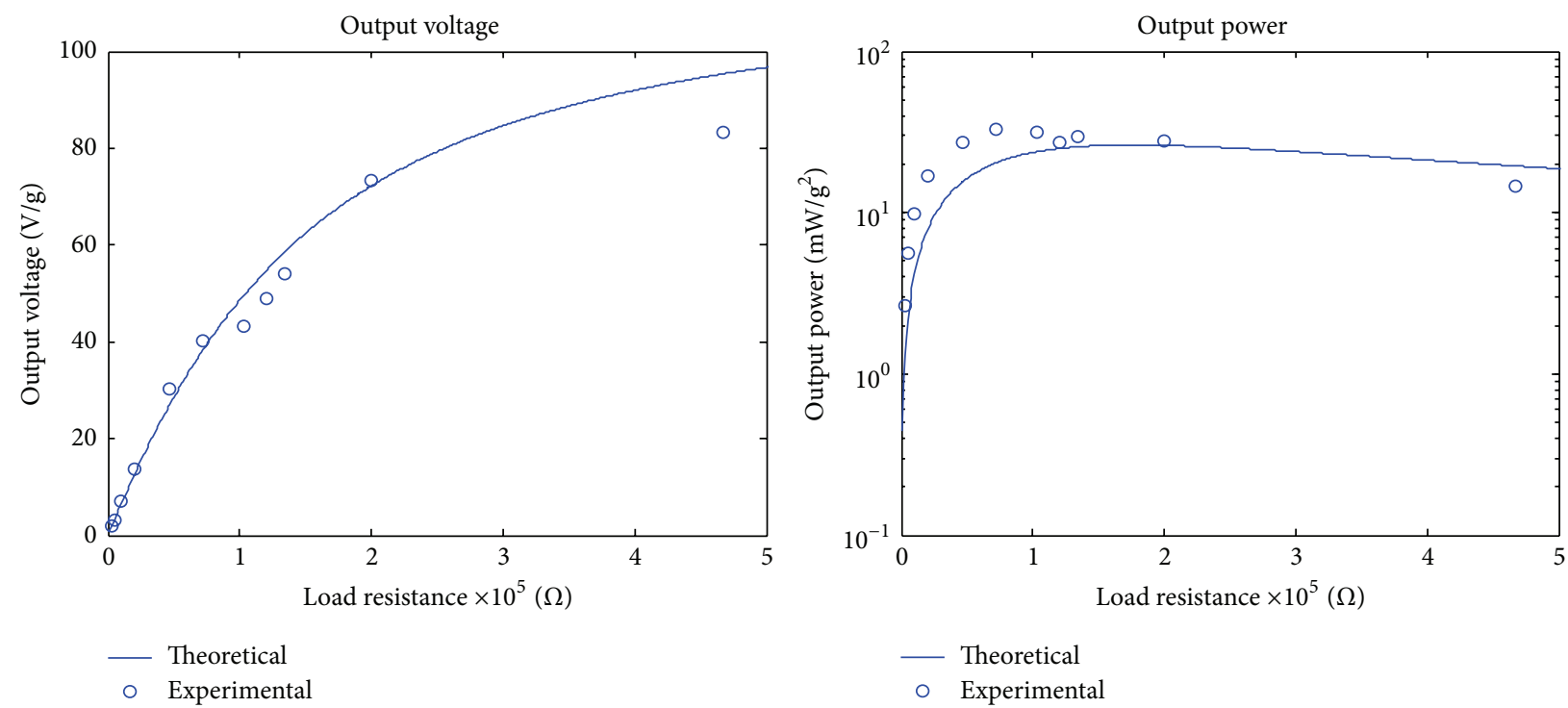

(b) Antiresonance state $f=32.35 \mathrm{~Hz}$

FIGURE 15: Output voltage and power of $\mathrm{CPEH}$ at resonance and antiresonance with the varying resistance.

may be weak to maintain compression and elongation in the longitudinal direction of the spring, such that transverse movement of the spring element may happen and buckling occurs.

From Figure 16 and Table 3, in the case of $a=10$ and $r=15$, the measured maximal output powers of the BPEH at the two optimal impedances are $377.7778\left(\mathrm{~mW} / \mathrm{g}^{2}\right)$ and $220.5760\left(\mathrm{~mW} / \mathrm{g}^{2}\right)$, respectively, which are 16 and 9 times that generated by the CPEH at load resistance $R_{\mathrm{L}}=470 \mathrm{k} \Omega$, respectively. And the frequency spaces between the two peaks at the two optimal impedances are 9 and $11 \mathrm{~Hz}$, respectively.

From Figure 17 and Table 3, in the case of $a=10$ and $r=7$, the measured maximal output powers of the BPEH at the two optimal impedances are $545.7817\left(\mathrm{~mW} / \mathrm{g}^{2}\right)$ and $542.5681\left(\mathrm{~mW} / \mathrm{g}^{2}\right)$, respectively, which are both about 24 times that generated by the $\mathrm{CPEH}$ at load resistance $R_{\mathrm{L}}=$ $470 \mathrm{k} \Omega$, respectively. And the frequency spaces between the two peaks at the two optimal impedances are both $14 \mathrm{~Hz}$.

Based on Table 3, as the stiffness ratio increases, the left peak power decreases and the right peak power increases under the same mass ratio. It is also found during the experiments that when the stiffness ratio is close to 100 , the left peak and the right peak of the power curve become one peak, whose frequency is close to the resonance frequency of the $\mathrm{CPEH}$.

The above results verify the validity of the improved lumped parameter model presented above, and the obtained results also indicate that the elastic magnifier added to 

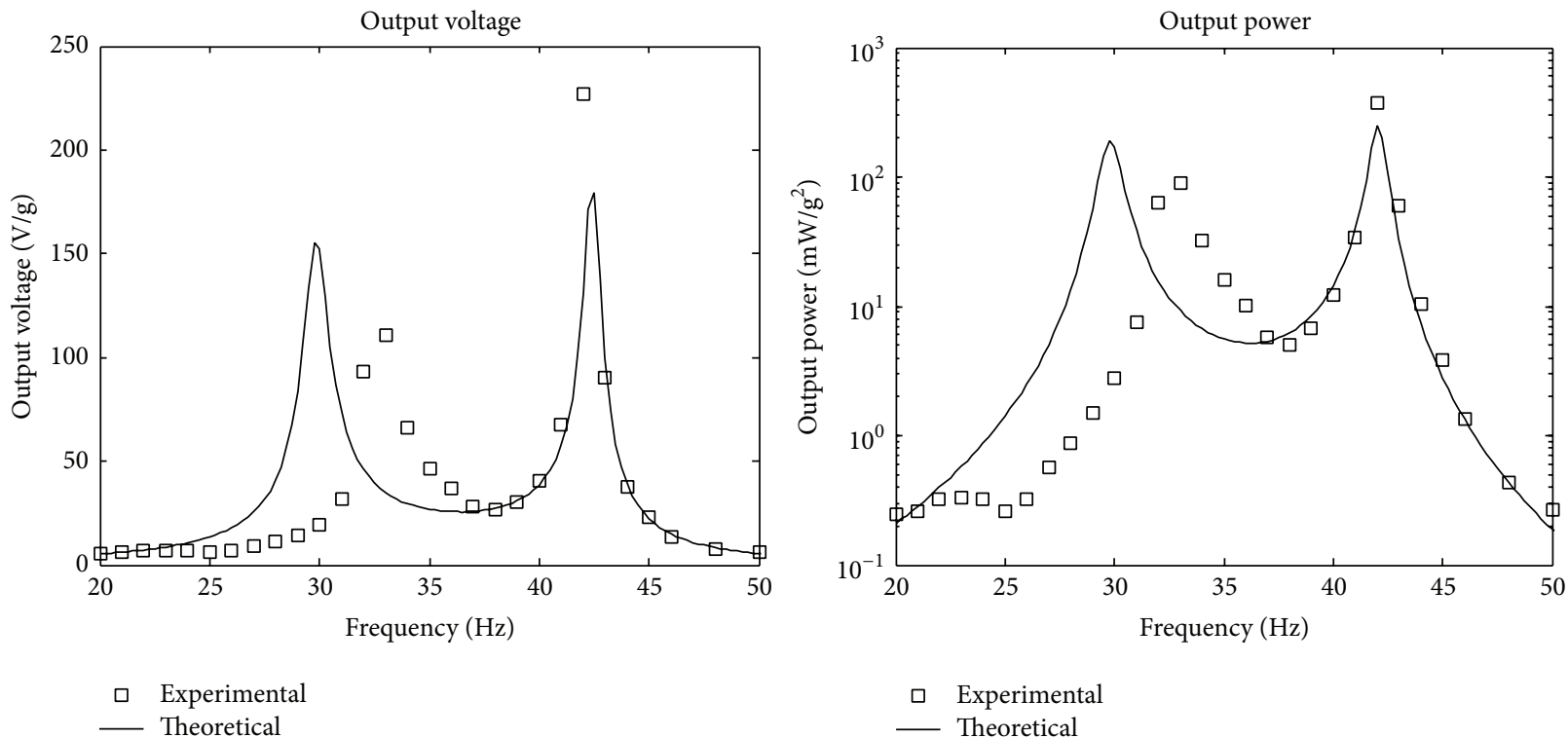

(a) Load resistance $R_{\mathrm{L}}=136 \mathrm{k} \Omega$
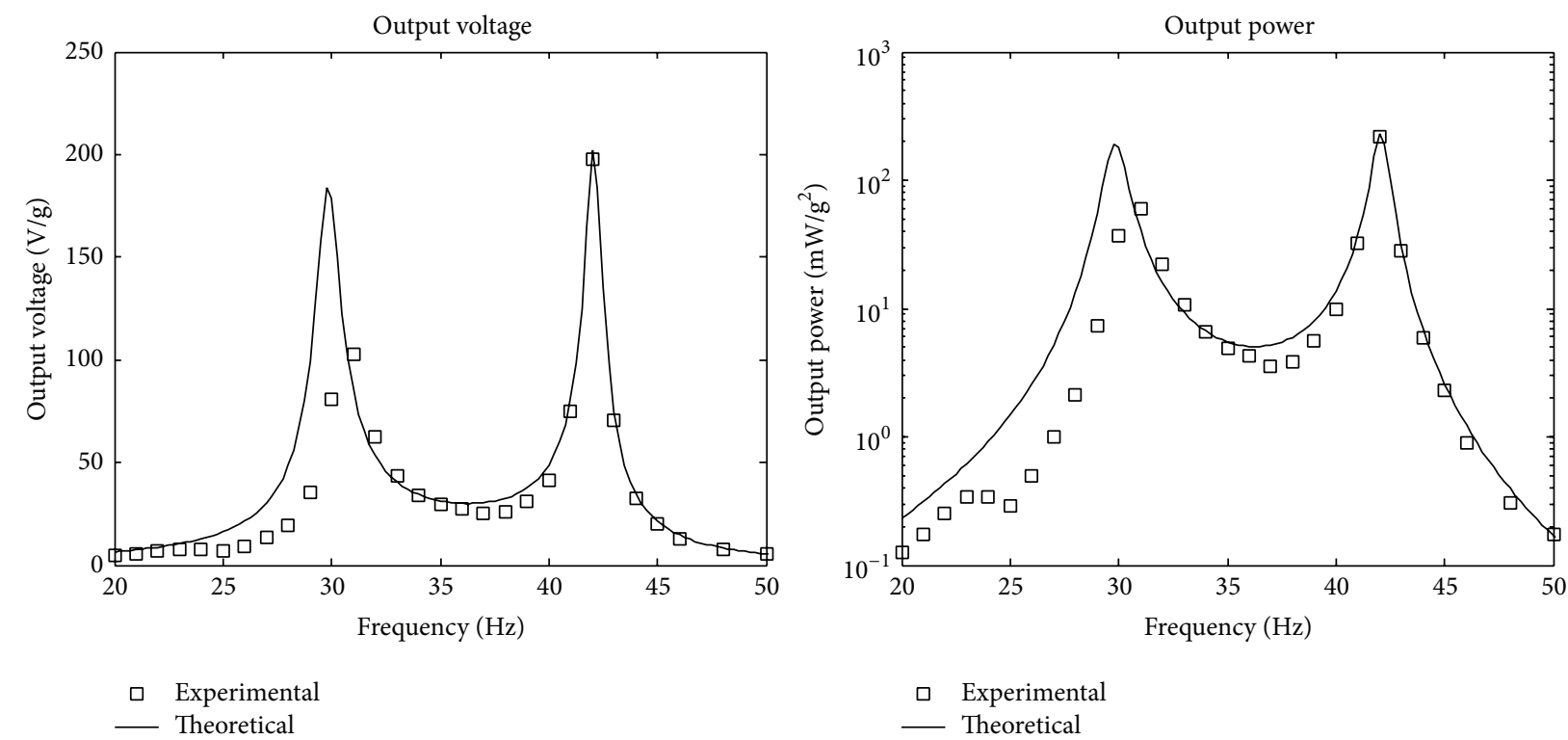

(b) Load resistance $R_{\mathrm{L}}=177 \mathrm{k} \Omega$

FIGURE 16: Frequency responses of output voltage and power of the BPEH under different load resistances when $a=10$ and $r=15$.

the CPEH cannot only enhance the output performances but also broaden the frequency bandwidth.

\section{Conclusions and Future Work}

A BPEH combining a $\mathrm{CPEH}$ with an elastic magnifier is presented to enhance the electromechanical properties. An improved lumped parameter electromechanical model is developed and testified by some experiments, and the design optimization problem of the BPEH is studied. Both the theoretical and the experimental results indicate that choosing an appropriate mass ratio and stiffness ratio of the $\mathrm{BPEH}$ can greatly improve the output voltage and output power. In the case of $a=10$ and $r=7$, the measured maximal output powers of the BPEH at the two optimal impedances are $545.7817\left(\mathrm{~mW} / \mathrm{g}^{2}\right)$ and $542.5681\left(\mathrm{~mW} / \mathrm{g}^{2}\right)$, respectively, which are both 24 times that generated by the CPEH at load resistance $R_{\mathrm{L}}=470 \mathrm{k} \Omega$. And the frequency spaces between the two peaks at the two optimal impedances are both $14 \mathrm{~Hz}$. Therefore, the inclusion of the elastic magnifier is beneficial to miniature generators in harvesting vibrational energy from the environment. 

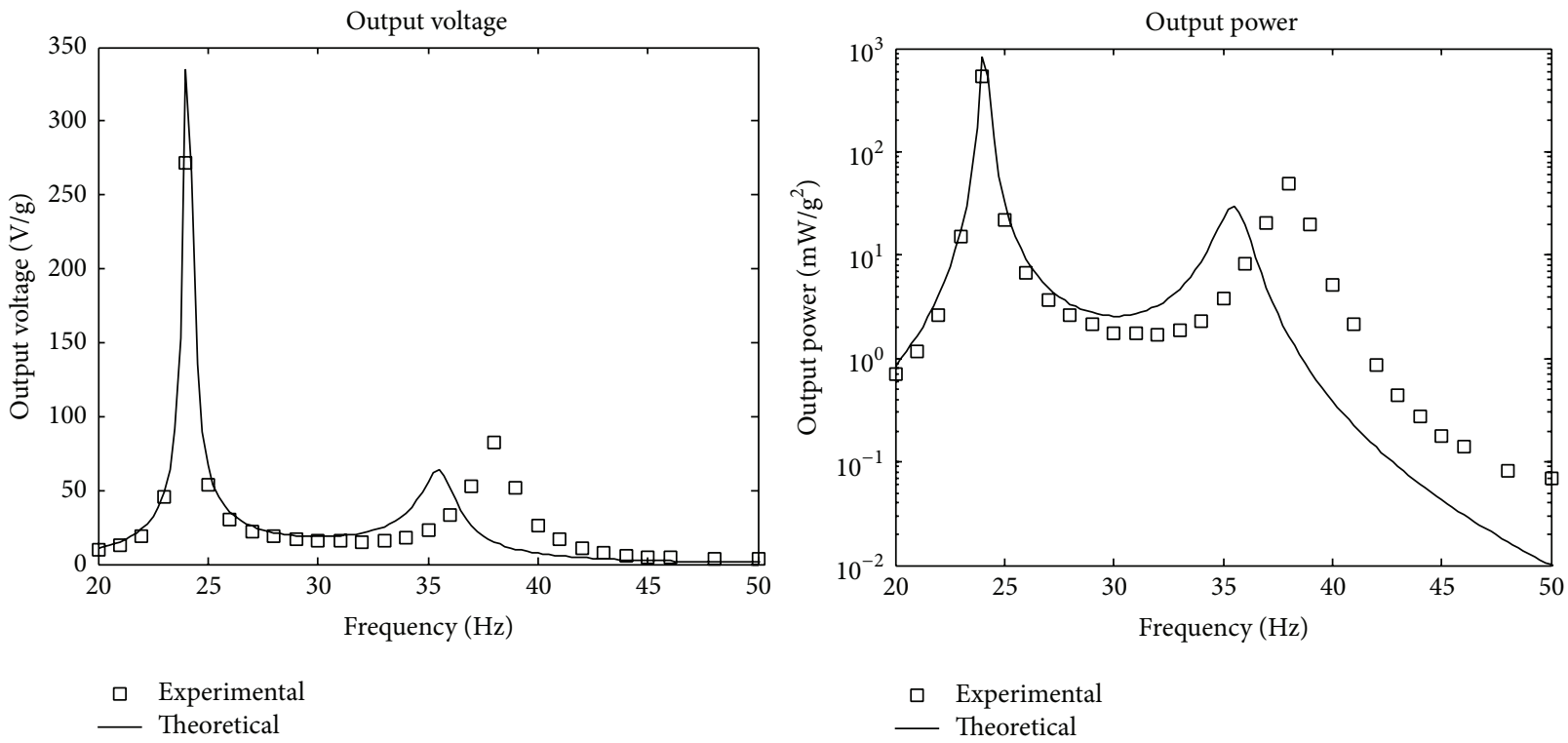

(a) Load resistance $R_{\mathrm{L}}=136 \mathrm{k} \Omega$
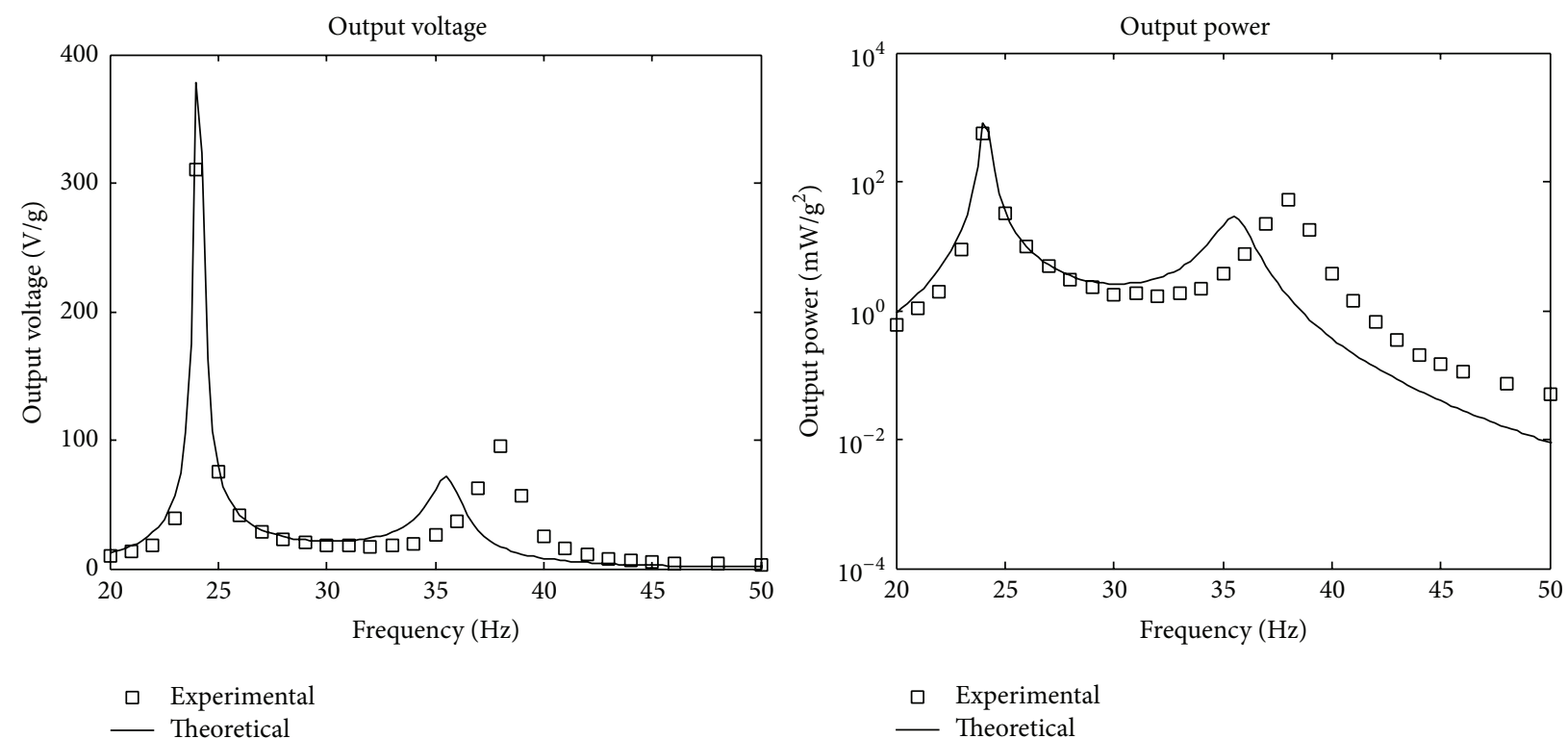

(b) Load resistance $R_{\mathrm{L}}=177 \mathrm{k} \Omega$

FIGURE 17: Frequency responses of output voltage and power of the BPEH under different load resistances when $a=10$ and $r=7$.

Concerning the vision of the proposed BPEH, when the mass ratio $a$ is larger than the critical mass ratio $a_{c}$, the electrical output of the BPEH is larger than that of the CPEH over a frequency range between $f_{\mathrm{r}}$ and $f_{\mathrm{ar}}$. However, from a practical viewpoint, the realization of a large mass ratio within the limited space of a BPEH will be challenging.

\section{Conflict of Interests}

The authors declare that there is no conflict of interests regarding the publication of this paper.

\section{Acknowledgments}

The authors gratefully acknowledge the support from the National Natural Science Foundation of China (no. 51277165) and Zhejiang Provincial Natural Science Foundation of China (no. LY15F10001).

\section{References}

[1] J. A. Paradiso and T. Starner, "Energy scavenging for mobile and wireless electronics," IEEE Pervasive Computing, vol. 4, no. 1, pp. 18-27, 2005. 
[2] N. S. Hudak and G. G. Amatucci, "Small-scale energy harvesting through thermoelectric, vibration, and radiofrequency power conversion," Journal of Applied Physics, vol. 103, no. 10, Article ID 101301, 2008.

[3] C. Ó. Mathúna, T. O’Donnell, R. V. Martinez-Catala, J. Rohan, and B. O’Flynn, "Energy scavenging for long-term deployable wireless sensor networks," Talanta, vol. 75, no. 3, pp. 613-623, 2008.

[4] C. B. Williams and R. B. Yates, "Analysis of a micro-electric generator for microsystems," Sensors and Actuators A: Physical, vol. 52, no. 1-3, pp. 8-11, 1996.

[5] P. D. Mitcheson, P. Miao, B. H. Stark, E. M. Yeatman, A. S. Holmes, and T. C. Green, "MEMS electrostatic micropower generator for low frequency operation," Sensors and Actuators, A: Physical, vol. 115, no. 2-3, pp. 523-529, 2004.

[6] S. Roundy, P. K. Wright, and J. Rabaey, "A study of low level vibrations as a power source for wireless sensor nodes," Computer Communications, vol. 26, no. 11, pp. 1131-1144, 2003.

[7] S. R. Anton and H. A. Sodano, "A review of power harvesting using piezoelectric materials (2003-2006)," Smart Materials and Structures, vol. 16, no. 3, pp. R1-R21, 2007.

[8] S. P. Beeby, M. J. Tudor, and N. M. White, "Energy harvesting vibration sources for microsystems applications," Measurement Science and Technology, vol. 17, no. 12, pp. R175-R195, 2006.

[9] W. H. Liao, D. H. Wang, and S. L. Huang, "Wireless monitoring of cable tension of cable-stayed bridges using PVDF piezoelectric films," Journal of Intelligent Material Systems and Structures, vol. 12, no. 5, pp. 331-339, 2001.

[10] N. E. duToit, B. L. Wardle, and S. G. Kim, "Design considerations for MEMS-scale piezoelectric mechanical vibration energy harvesters," Integrated Ferroelectrics, vol. 71, pp. 121-160, 2005.

[11] M. F. Daqaq, J. M. Renno, J. R. Farmer, and D. J. Inman, "Effects of system parameters and damping on an optimal vibration-based energy harvester," in Proceedigs of the 48th AIAA/ASME/ASCE/AHS/ASC Structures, Structural Dynamics, and Materials Conference, vol. 8, pp. 7901-7911, Honolulu, Hawaii, USA, April 2007.

[12] W. Wu, Y. Chen, and B. Lee, "Tunable resonant frequency power harvesting devices," in Smart Structures and Materials 2006: Damping and Isolation, vol. 6169 of Proceedings of SPIE, 61690A, The International Society for Optical Engineering, March 2006.

[13] C. Eichhorn, F. Goldschmidtboeing, and P. Woias, "Bidirectional frequency tuning of a piezoelectric energy converter based on a cantilever beam," Journal of Micromechanics and Microengineering, vol. 19, no. 9, Article ID 094006, 2009.

[14] V. R. Challa, M. G. Prasad, Y. Shi, and F. T. Fisher, "A vibration energy harvesting device with bidirectional resonance frequency tunability," Smart Materials and Structures, vol. 17, no. 1, Article ID 015035, 2008.

[15] A. Erturk and D. J. Inman, "Broadband piezoelectric power generation on high-energy orbits of the bistable Duffing oscillator with electromechanical coupling," Journal of Sound and Vibration, vol. 330, no. 10, pp. 2339-2353, 2011.

[16] S. C. Stanton, C. C. McGehee, and B. P. Mann, "Nonlinear dynamics for broadband energy harvesting: investigation of a bistable piezoelectric inertial generator," Physica D: Nonlinear Phenomena, vol. 239, no. 10, pp. 640-653, 2010.

[17] Y. Tadesse, S. Zhang, and S. Priya, "Multimodal energy harvesting system: piezoelectric and electromagnetic," Journal of Intelligent Material Systems and Structures, vol. 20, no. 5, pp. 625-632, 2009.
[18] P. J. Cornwell, J. Goethal, J. Kowko, and M. Damianakis, "Enhancing power harvesting using a tuned auxiliary structure," Journal of Intelligent Material Systems and Structures, vol. 16, no. 10, pp. 825-834, 2005.

[19] A. Erturk, J. M. Renno, and D. J. Inman, "Modeling of piezoelectric energy harvesting from an L-shaped beam-mass structure with an application to UAVs," Journal of Intelligent Material Systems and Structures, vol. 20, no. 5, pp. 529-544, 2009.

[20] C. T. Pan, Z. H. Liu, and Y. C. Chen, "Study of broad bandwidth vibrational energy harvesting system with optimum thickness of PET substrate," Current Applied Physics, vol. 12, no. 3, pp. 684-696, 2010.

[21] N. A. Kong, D. S. Ha, A. Erturk, and D. J. Inman, "Resistive impedance matching circuit for piezoelectric energy harvesting," Journal of Intelligent Material Systems and Structures, vol. 21, no. 13, pp. 1293-1302, 2010.

[22] H.-Y. Wang, X.-B. Shan, and T. Xie, "An energy harvester combining a piezoelectric cantilever and a single degree of freedom elastic system," Journal of Zhejiang University: Science A, vol. 13, no. 7, pp. 526-537, 2012.

[23] P. S. Ma, J. E. Kim, and Y. Y. Kim, "Power-amplifying strategy in vibration-powered energy harvesters," in Active and Passive Smart Structures and Integrated Systems, vol. 7643 of Proceedings of SPIE, April 2010.

[24] W. Li, T. S. Liu, and C. C. Hsiao, "A miniature generator using piezoelectric bender with elastic base," Mechatronics, vol. 21, no. 7, pp. 1183-1189, 2011.

[25] O. Aldraihem and A. Baz, "Energy harvester with a dynamic magnifier," Journal of Intelligent Material Systems and Structures, vol. 22, no. 6, pp. 521-530, 2011.

[26] M. Arafa, W. Akl, and A. Aladwani, "Experimental implementation of a cantilevered piezoelectric energy harvester with a dynamic magnifier," in Active and Passive Smart Structures and Integrated Systems 2011, 79770Q, vol. 7977 of Proceedings of the SPIE, p. 9, April 2011.

[27] X. D. Tang and L. Zuo, "Enhanced vibration energy harvesting using dual-mass systems," Journal of Sound and Vibration, vol. 330, no. 21, pp. 5199-5209, 2011.

[28] G. Q. Wang, W. P. Jin, Y. Z. Zhan, and Y. M. Lu, "A forceelectric coupling model and power optimization of piezoelectric vibration energy harvester," Chinese Journal of Sensors and Actuators, vol. 26, no. 8, pp. 1092-1100, 2013 (Chinese).

[29] A. Erturk and D. J. Inman, "A distributed parameter electromechanical model for cantilevered piezoelectric energy harvesters," Journal of Vibration and Acoustics, vol. 130, no. 4, Article ID 041002, 2008.

[30] Y. C. Shu and I. C. Lien, "Analysis of power output for piezoelectric energy harvesting systems," Smart Materials and Structures, vol. 15, no. 6, pp. 1499-1512, 2006.

[31] D. G. Alciatore, Introduction to Mechatronics and Measurement Systems, McGraw Hill, 3rd edition, 2007.

[32] A. Erturk and D. J. Inman, "An experimentally validated bimorph cantilever model for piezoelectric energy harvesting from base excitations," Smarts Materials and Structures, vol. 18, no. 2, pp. 1-18, 2009. 


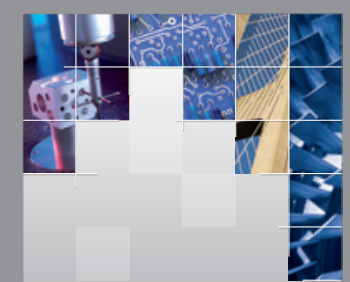

\section{Enfincering}
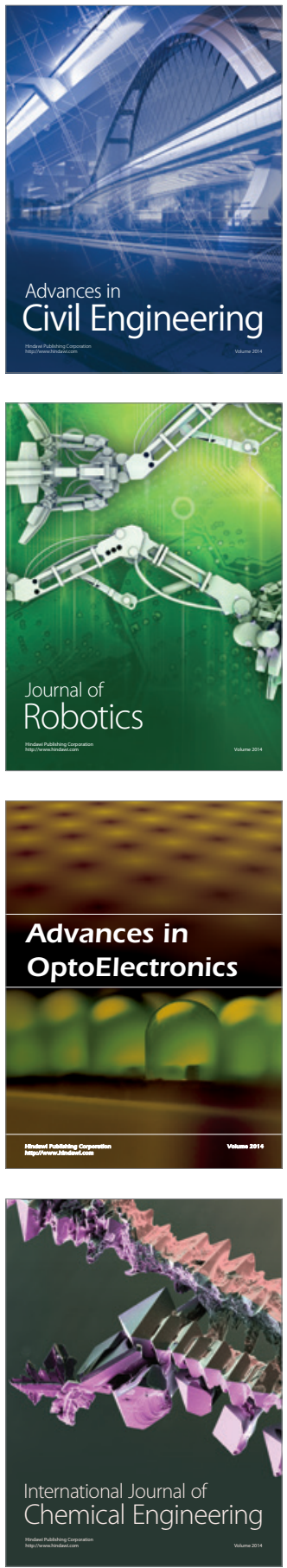

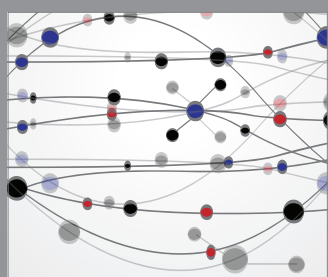

The Scientific World Journal

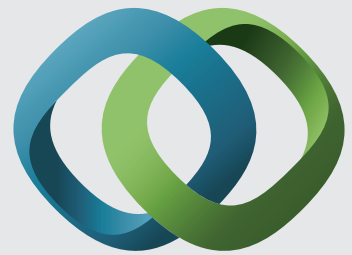

\section{Hindawi}

Submit your manuscripts at

http://www.hindawi.com
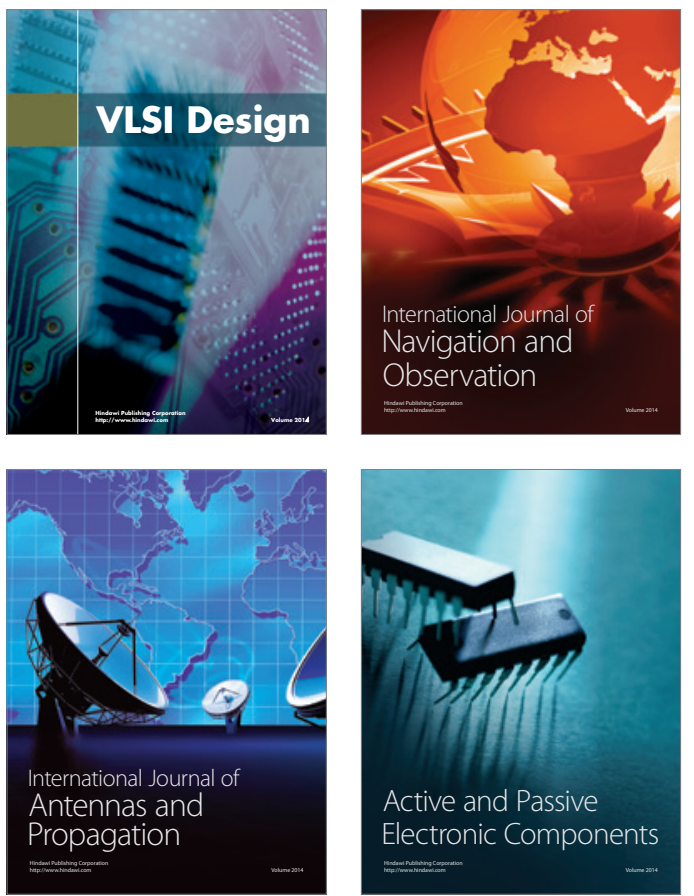
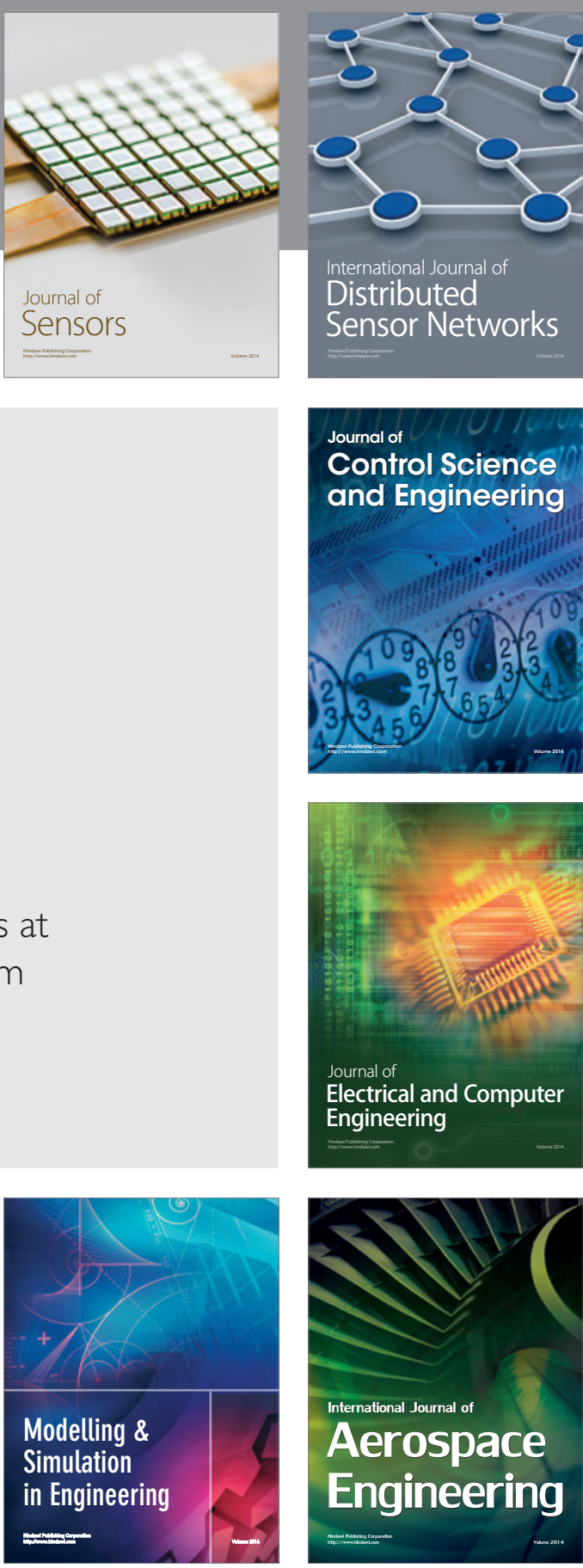

International Journal of

Distributed

Sensor Networks

Journal of

Control Science

and Engineering
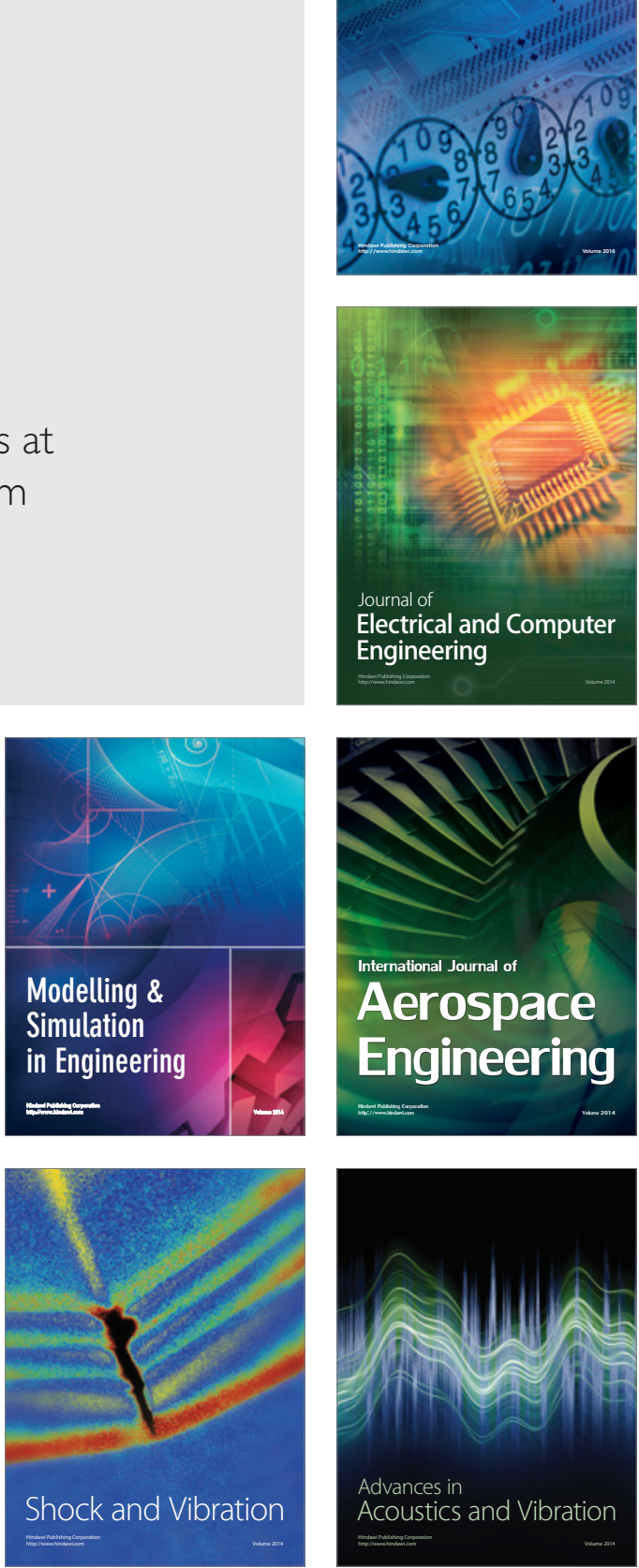